\title{
Climate of the last millennium: a sensitivity study
}

\author{
By CÉDRIC BERTRAND ${ }^{1 *}$, MARIE-FRANCE LOUTRE, MICHEL CRUCIFIX, and \\ ANDRÉ BERGER, ${ }^{1}$ Royal Meterological Institute of Belgium, Brussels, Belgium; Institut d'Astronomie \\ et de Géophysique G. Lemaître, Université catholique de Louvain, chemin du cyclotron, 2 B-1348 Louvain- \\ la-neuve, Belgium
}

(Manuscript received 5 February 2001; in final form 13 September 2001)

\begin{abstract}
Seventy-one sensitivity experiments have been performed using a two-dimensional sectoraveraged global climate model to assess the potential impact of six different factors on the last millennium climate and in particular on the surface air temperature evolution. Both natural (i.e, solar and volcanism) and anthropogenically-induced (i.e. deforestation, additional greenhouse gases, and tropospheric aerosol burden) climate forcings have been considered.

Comparisons of climate reconstructions with model results indicate that all the investigated forcings are needed to simulate the surface air temperature evolution. Due to uncertainties in historical climate forcings and temperature reconstructions, the relative importance of a particular forcing in the explanation of the recorded temperature variance is largely function of the forcing time series used. Nevertheless, our results indicate that whatever the historical solar and volcanic reconstructions may be, these externally driven natural climate forcings are unable to give climate responses comparable in magnitude and time to the late-20th-century temperature warming while for earlier periods combination of solar and volcanic forcings can explain the Little Ice Age and the Medieval Warm Period. Only the greenhouse gas forcing allows the model to simulate an accelerated warming rate during the last three decades. The best guess simulation (largest similarity with the reconstruction) for the period starting $1850 \mathrm{AD}$ requires however to include anthropogenic sulphate forcing as well as the impact of deforestation to constrain the magnitude of the greenhouse gas twentieth century warming to better fit the observation. On the contrary, prior to $1850 \mathrm{AD}$ mid-latitude land clearance tends to reinforce the Little Ice age in our simulations.
\end{abstract}

\section{Introduction}

Detection and attribution of recent climate change (e.g. the search for evidence of anthropogenic climate change) is still an open question although some answers become now available (e.g. Hegerl et al., 1997; Barnett et al., 1999; Tett et al., 1999; Stott et al., 2001). Recently, using a stateof-the art climate model to investigate the origin of the 20th century warming, Stott et al. (2000) showed that natural climate forcings alone cannot

\footnotetext{
* Corresponding author. e-mail: cedric@astr.ucl.ac.be
}

account for the increase in global temperature in recent decades. However, because of the limited time span covered by their simulations, of the overall upward trend in both temperature and several forcings, of the uncertainty associated with the magnitude of the natural climate forcing, and of the uncertainty on the mechanism and magnitude of anthropogenic aerosol forcing, it is difficult to separate the individual effects of the various factors on recent climate changes. Extending the study over a longer time interval is one way to avoid this problem (Free and Robock, 1999). It allows also to place the warming of the 20 th century within its historical context and to

Tellus 54A (2002), 3 
test various historical reconstructions of natural climate forcings.

For an accurate assessment of the relative role of natural variability and anthropogenic influence in the Earth's climate, reconstructions of past temperatures from the pre-industrial as well as the industrial periods are essential. Widespread instrumental climate data are typically available for not more than the past 150 years. Moreover, these records may have biases due to contamination by the anthropogenic impact itself (by changing measurements methods and/or instruments, for example), and they do not cover the whole Earth. Reconstructions of pre-industrial climate have to rely principally on proxy palaeoclimate records (e.g. tree rings, coral records, ice cores), each with their own particular strengths and limitations. Moreover, a further difficulty encountered to reconstruct temperature fluctuations of the last millennium is that they were small, probably less than $1^{\circ} \mathrm{C}$. Not all the climate proxies are accurate enough to allow for relevant climate records over the last millennium. As an example, Broecker (2001) estimated that for time scales greater than a century or two, only the reconstruction of temperatures from the elevation of mountain snowlines and borehole thermometry could yield temperatures that are accurate to $0.5^{\circ} \mathrm{C}$. Despite these limitations, several reconstructions of large-scale temperature changes have been made with various sets of paleoclimate data, from tree rings and ice cores to corals, sediments and historical records (Jones et al., 1998; Mann et al., 1998, 1999; Crowley and Lowery, 2000). These reconstructions point to a general decline in temperature from about 1000 to $1900 \mathrm{AD}$, and a rapid warming over the last century that has no counterpart in the millennial record.

While it is now recognized that fully coupled global circulation models (GCM) of the atmosphere and ocean (AOGCM) are state of the art for climate simulation, there are still limited in the number of experiments they can perform over many centuries. As an alternative, Crowley and Kim (1999) used a linear energy balance model (EBM; Kim and Crowley, 1994) to estimate the temperature response to changes in some forcings over the last few centuries and they compared their results with paleo-reconstructions of temperature. Extending this approach over the past 1000 years, Crowley (2000) reported that 41 to $64 \%$ of the pre-anthropogenic low-frequency variance in temperature can be accounted for by volcanism and solar variability.

Here, we would like to question one of Crowley's (2000) implicit assumptions that the Northern hemisphere annual mean temperature fluctuations over the past millennium are similar to the annual and global mean temperature variations. Indeed, Crowley (2000) compared and discussed simulated annual and global mean temperature time series (since his energy balance model calculates only annual and global mean temperature) and Northern hemisphere temperature reconstructions (Mann et al., 1999; Crowley and Lowery, 2000). But, because the amount and distribution of the continents and oceans differ between the two hemispheres, the hemispheric mean temperature response to a given climate forcing can largely be different from one hemisphere to the other. Moreover, some forcings, such as generated by anthropogenic sulphate, exhibit a strong regional dependency. Therefore hemispherical mean response and global mean response can differ significantly.

Our simulations are complementary to Crowley (2000). A two-dimensional (latitude-altitude) global climate model of intermediate complexity was used to assess the potential impact of six factors on the surface air temperature over the last millennium. According to Brovkin et al. (1999) deforestation related to land conversion to agriculture over the past millennium could have caused a global cooling. In addition to the four climate forcings considered by Crowley (i.e. volcanism, solar variability, greenhouse gases, and anthropogenic sulphates) we have therefore included the vegetation change in our sensitivity study. Moreover, change in insolation geometry has also been included. Bertrand and van Ypersele (1999) have shown that while the climatic impact of the modification in the annual mean insolation received at the top of the atmosphere is negligible at the secular time scale, the behaviour can be quite different for a particular month.

The next section describes the climate model used in this study. The different climate forcings considered are presented in section 3. The results of our experiments are discussed in section 4 . Finally, conclusions are given in section 5 .

\section{Climate model description}

All simulations were carried out using the Louvain-la-Neuve two-dimensional sector-aver- 
aged global climate model. This model which links together the atmosphere, the hydrosphere, the terrestrial surface and the cryosphere of both hemispheres (Crucifix et al., 2001) is latitude, altitude, and time-dependent and is designed for simulating the seasonal cycle of both hemispheres. The surface is represented on a $5^{\circ}$ latitudinal grid and each latitudinal band is divided in longitude into a maximum of thirteen sector types. The Eurasian continent and the American continent are represented. The oceanic fractions are linked to the Atlantic, the Pacific, and the Indian basins. In this model, the horizontal grid boxes are equally spaced in latitude and defined as fractions in longitude. The ocean is represented on a $5^{\circ}$ latitudinal grid and with a 19-level vertical resolution. Ocean bottom topography is taken into account.

The atmosphere dynamics is represented by a zonally averaged two-level quasi-geostrophic (QG) model written in pressure coordinates (Sela and Wiin-Nielsen, 1971) and applied independently over each hemisphere. The numerical implementation follows Gallée et al. (1991) but considers the whole Earth instead of the Northern hemisphere only. The prognostic variables for the atmosphere are QG potential vorticities (Holton, 1979 ) at $250 \mathrm{hPa}$ and $750 \mathrm{hPa}$. The model allows to diagnose the temperature at $500 \mathrm{hPa}$ and the vorticity at $250 \mathrm{hPa}$ and $750 \mathrm{hPa}$, the latter being linearly extrapolated to the surface. An additional parameterization of the Hadley cell is implemented to account for the transports of heat, water-vapor and angular momentum by the mean meridional circulation in tropical latitudes. This parameterization presents also the advantage to allow for interhemispheric exchanges in the atmosphere.

Precipitation, vertical radiative (solar and infrared) and turbulent (sensible and latent) heat fluxes, and surface friction are also represented and provide a coupling between the atmosphere and the surface. Separate energy balance is calculated over each surface type at each latitude. At the top of the model, solar and IR fluxes contribute to the net energy flux available to the system. The heating of the atmosphere due to the vertical heat fluxes is the weighted average of the convergence of these fluxes above each kind of surface.

Evaporation follows Gallée et al. (1991) and resorts to the concept of water availability (Saltzman, 1980). The vertically integrated water vapor (WV) is transported both by the mean meridional circulation and the transient eddies. The latter are represented as a diffusive process using an exchange coefficient consistent to QG eddy transport. The precipitation, that is computed at each time step for each zonal band assuming the steady state approximation for the global WV content (e.g. Schmittner et al., 2000), is distributed over the 3 oceanic basins and the 2 continents from the ratios derived from presentday statistics by Jaeger (1976). Finally, runoff is implicitly represented by multiplying the precipitation over the oceans by a factor $\alpha$ such that the freshwater budget over the global ocean is zero at each time step.

The transfer of sensible heat from the surface to the atmosphere by convection is parameterized according to Saltzman and Ashe (1976). On each latitudinal band, the transfer of latent heat on a particular sector from surface to the atmosphere is parameterized according to Saltzman (1980). It depends on the surface temperature, on the surface relative humidity, on the computed wind, and on the vertical turbulent sensible heat flux, and is set proportional to the surface water availability which is calculated according to Gallée et al. (1991). On snow-free continent, it is function of the precipitation-evaporation budget over the year. On snow and sea-ice, water availability depends on temperature and is set equal to 1 over the free ocean.

Calculation of the radiative fluxes requires to know the vertical temperature profile and the vertical distribution of the main optically active constituents above the different surface types. Note that an effective single cloud is assumed to exist in each latitudinal belt, with annual mean cloud amounts (Ohring and Adler, 1978) supposed to be equal over each surface type; monthly variations of the zonal cloudiness being introduced by superimposing a seasonal cycle on the annual mean values following the monthly mean data of Berlyand and Strokina (1980). Given the averaged temperature at $500 \mathrm{hPa}$, the vertical temperature profile in the troposphere is determined by assuming that the product of the static stability and pressure remains constant along the vertical. Near the surface the temperature profile is modified so that the air has the same temperature as the surface. Such a correction is necessary to allow, for example, thermal inversions over cold surfaces. The stratosphere is supposed to be isothermal 
with a temperature identical to that of the tropopause. Tropopause height is parameterized as a function of the zonally averaged surface temperature following Sellers (1983). It must be noted that unlike the atmospheric dynamics, the radiative transfer computation uses 10 to 15 layers, the exact number depending on the surface pressure over each surface type. The description of the atmospheric radiative transfer is given in Bertrand (1998).

In each latitudinal belt, the continent is divided into land and ice sheet, land being possibly covered partly by snow. The VECODE model (Brovkin et al., 1997) provides for each continent and each latitude the relative cover of tree, grass and potential desert. Surface temperature on each surface type is considered as a prognostic variable, the subsurface heat transfer obeying the relation of Taylor (1976) that considers a 12-month oscillation for subsurface heat storage. The albedo of snow free continental area is computed as the weighted averaged albedo of desert, grass and forest. Snow covered area is a function of snow precipitation frequency and snow surface temperature. The effect of the solar zenith angle on the snow albedo is also taken into account (Gallée et al., 1991). The effect of forest-taiga respective fractions on snow albedo is parameterized, the maximum snow albedo (excluding the zenith angle effect) being computed as in Harvey (1986).

Within each individual oceanic basin (Atlantic, Pacific and Indian), the ocean model is based on the zonally averaged form of the multi-level primitive equation model by Bryan (1969) and Semter (1986). This model is extensively described in Hovine and Fichefet (1994) except for some modifications given hereafter. The east-west pressure difference which arises on averaging the momentum equations is taken to be proportional to the meridional pressure gradient as in Wright and Stocker (1992). In the North, lateral exchanges of heat and salt between the Atlantic and Pacific basins are permitted between 85 and $90^{\circ} \mathrm{N}$. In the South, the three basins are interconnected between 40 and $65^{\circ} \mathrm{S}$ where zonal advection and diffusion are represented. The Drake passage and the Indian-Pacific connection are 4000-m deep while the Atlantic and Indian basins are interconnected over the whole ocean depth (5000 m).

A Lax-Wendroff scheme provides numerical horizontal advection stability. Whenever the vertical density profile is unstable, convection is represented through an enhanced vertical diffusivity (Goosse and Fichefet, 1999). Another recent evolution is the implementation along Antarctica of a downsloping flow scheme based on Campin and Goosse (1999). Such a scheme allows for a better representation of deep water formation.

A simple thermodynamic-dynamic sea-ice model is coupled to the ocean model. It simulates mainly sea ice and its covering snow layer, and leads. Separate computations are performed for the vertical ice growth and melting and for the lateral growth and decay. Vertical ice formation and ablation representation are based on the 0-layer thermodynamic model of Semtner (1976) modified by Harvey $(1988,1992)$. Leads are taken into account following the approach of Parkinson and Washington (1979) adapted by Harvey (1988). White ice is accounted for following Harvey (1988). For the ice advection, a one-dimensional meridional advection scheme is used with ice velocities prescribed as in Harvey (1988).

The atmosphere, sea-ice and ocean components are synchronously coupled with a time step of 2 days.

In Crowley (2000), the model used to calculate the annual mean temperature is a linear upwelling/diffusion energy balance model. This model (Kim and Crowley, 1994) calculates the temperature of a vertically averaged mixed-layer ocean/atmosphere that is a function of forcing changes and radiative damping. The mixed layer is coupled to the deep ocean with an upwelling/diffusion equation in order to allow for heat storage in the ocean interior. The radiative damping term is adjusted to embrace an equilibrium sensitivity of $2{ }^{\circ} \mathrm{C}$ for a double $\mathrm{CO}_{2}$ concentration.

\section{Climate forcings reconstruction}

\subsection{Solar forcing}

Due to the lack of direct measurements of solar radiation at the climatological time scale (direct solar monitoring extends only over the last two solar cycles -about 22 years-) and the absence of a physical theory able to explain the origin of the observed irradiance variation, different solar indices measured over the past centuries have been 
used to compute the total solar irradiance (TSI). Unfortunately such proxies (e.g. the fraction of penumbral spots, the length of the solar cycle, the changes in the equatorial solar rotation rate, the decay rate of the solar cycle, the mean level of solar activity, the geomagnetic aa index) extend only back to the 17 th century due to the lack of reliable observation of solar activity before the invention of the telescope (1610 AD). However, some authors (e.g. Lean et al., 1992; Zhang et al., 1994; Solanki and Fligge, 1998) have shown that, assuming a linear relationship between magnetic activity and irradiance, the concomitant production of ${ }^{14} \mathrm{C}$ and ${ }^{10} \mathrm{Be}$ can also be used as a proxy for the TSI. (Magnetic fields of the solar wind deflect the primary flux of charged cosmic particles which leads to a reduction of cosmogenic nuclide production in the Earth's atmosphere).

Recently, a time series of the solar magnetic variability over the last 1200 years based on a quantitative study of the common fluctuations of ${ }^{14} \mathrm{C}$ and ${ }^{10} \mathrm{Be}$ production rates was converted into irradiance variations by Bard et al. (2000). This conversion was performed by linear scaling based on previous studies of Sun-like stars and of the Sun's behaviour over the last few centuries as provided by different TSI reconstructions. Here, we have investigated the response of our model to the upper and lower range of TSI variations over the last millennium as reconstructed by Bard et al. (2000). The first one (TSI_R) based on the reconstruction by Reid (1997) oscillates around a mean value of $1364.24 \mathrm{~W} \mathrm{~m}^{-2}$ (standard deviation is $3.95 \mathrm{~W} \mathrm{~m}^{-2}$, maximum amplitude of $19.26 \mathrm{~W} \mathrm{~m}^{-2}$ ). This constitutes an extreme for the range of TSI variations. The second TSI reconstruction (TSI_L), is based on factors derived from Lean et al. (1995) (mean value is $\quad 1365.50 \mathrm{~W} \mathrm{~m}^{-2}$, standard deviation is $1.25 \mathrm{~W} \mathrm{~m}^{-2}$, and maximum amplitude of $5.6 \mathrm{~W} \mathrm{~m}^{-2}$ ). Beside these two TSI reconstructions, we also considered the Sol.Be10 time series derived by Crowley (2000) from the Beryllium 10 measurements of Bard et al. (2000). Only the Sol.Be10 time series has been considered amongst the three different solar indices used in Crowley (2000) since the ${ }^{10} \mathrm{Be}$ could be the most reliable of the solar indices (Crowley, personal communication). These three different TSI time series are displayed in Fig. 1 (panel
A.1) for comparison. Note that by contrast to the energy balance model by Crowley (2000) which needs a net radiative forcing, our model rather requires to be forced in term of TSI value. Then the Crowley Sol.Be10 time series has been converted into TSI by accounting for a $30 \%$ albedo of the Earth atmosphere.

Finally, to account for the 'astronomical' or 'Milankovitch effect' (hereafter referred as 'MIL') in our numerical simulations, the seasonal cycle of the incoming solar radiation at the top of the atmosphere for each latitude was permitted to vary according to Berger (1978).

\subsection{Volcanic forcing}

While theoretical consequences and mechanisms of specified atmospheric aerosol loadings from volcanic events have been widely investigated (see e.g. Pollack et al., 1976; Hansen et al., 1978; Harshvardhan, 1979; Hansen et al., 1980; Pollack et al., 1981), historical volcanic perturbations are only poorly documented (e.g. Lamb, 1970). In accordance with a previous study (Bertrand et al., 1999), the calibrated optical depth values as derived by Zielinski (1995) from the Greenland Ice Sheet Project 2 (GISP2) volcanic $\mathrm{SO}_{4}^{2-}$ has been used to account for the volcanic forcing up to 1850 . After 1850 the monthly mean (latitude dependent) stratospheric aerosol optical depth of Sato et al. (1993, updated) is used. In the following we will refer to the whole time series (Zielinski GISP2 data extended by the Sato's values) as VOL_Z. In addition to this 1000-year-long volcano time series, we also have taken into account the volcano time series reconstructed by Crowley (2000). The total number of volcanoes in Crowley is significantly greater than in Zielinski because it includes the Crete record (Hammer et al., 1980) in addition to the Zielinski GISP2 record and it was adjusted taking in account the Langway's study of bipolar ice cores (Langway et al., 1995). This second time series (hereafter referred to as VOL_C has been extended from 1960 to 1999 by using the monthly mean values of Sato et al. (1993, updated). These different volcano time series are displayed in Fig. 1 (panel B.1) for comparison.

Lacis et al. (1992) suggested that the change of the net radiative flux at the tropopause, $\Delta F_{\text {net }}$, 

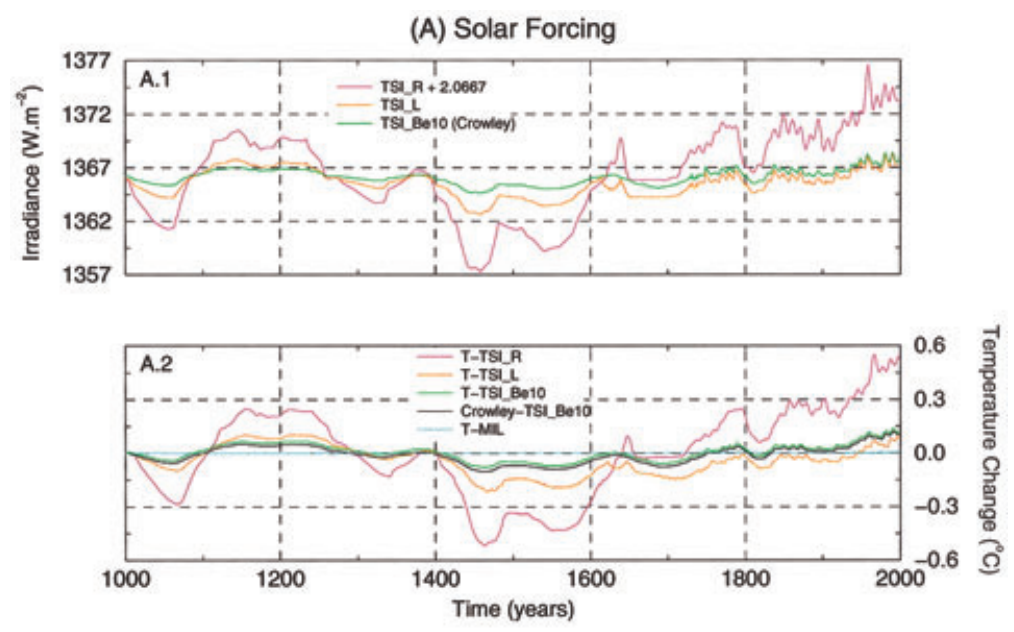

(B) Volcanic Forcing
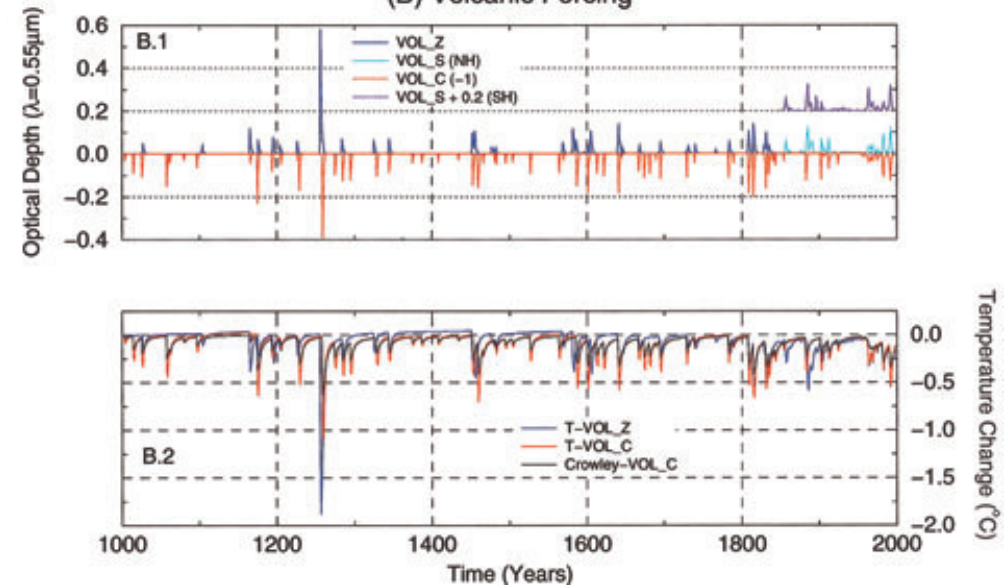

Fig. 1. Individual natural forcings time series and model responses. (A) Solar forcing: A.1 Comparison between three different TSI reconstructions. TSI_R and TSI_L are from Bard et al. (2000) while TSI_Be10 is computed from the Crowley (2000) Be10 net radiative forcing. A.2 Transient response of the annual global mean surface air temperature to the solar forcings of A.1. The different abbreviations for the TSI responses refer to the different indices used. MIL refers to the model response to the Milankovitch forcing. (B) Volcanic forcing: B.1 Comparison between two volcanic time series. VOL_Z refers to time series computed from the Zielinski (1995) GISP2 record, while VOL_C is the volcanic time series used in Crowley (2000) (multiplied by -1 for display purpose). VOL_S is the Sato et al. (1993) stratospheric aerosol optical depth reconstruction updated to 1999. B.2 Transient response of the annual global mean surface air temperature to the volcanic forcings. Crowley model responses (2000) are displayed for comparison (black curves in panels A.2 and B.2). Temperature anomalies are given relative to the equilibrium state.

caused by an additional globally uniform stratospheric aerosol layer can be approximated by

$\Delta F_{\text {net }}\left(\mathrm{W} / \mathrm{m}^{2}\right) \sim 30 \tau$

where $\tau$ is the optical depth (at $\lambda=0.55 \mu \mathrm{m}$ ). Based on this formulation, Crowley (2000) con- verted the stratospheric aerosol optical depth into a net radiative forcing. The reverse transformation was applied here since the volcanic forcing is introduced in our climate model through the changes in the optical properties of the stratospheric layer. 


\subsection{Vegetation changes}

Vegetation and land surface covers have changed significantly over the past. Over the past few centuries forests have been removed for agriculture practices in many countries, in particular in mid latitudes. In Europe, deforestation started more than 2000 years ago, but a very large deforestation (up to the mountain regions) took place during the Middle Age (since 1000 AD). The replacement of natural forests by cultivated fields and pasture lands reached a peak in the 11th, 12 th, and 13th centuries. The wood was also intensively used in local factories. It is only at the end of the 18th century that pressure on the forests was reduced because of a more efficient agriculture and the use of coal in factories (see e.g. Houghton et al., 1982).

These vegetation changes are important for climate because the surface albedo is not only related to the snow and ice fields, but also to the nature of vegetation which covers the land surfaces. It can also have an effect on the amount of rainfall because there is more evaporation and consequently more water vapour in the air over forests than over grassland or desert. A scenario of vegetation change since $1000 \mathrm{AD}$ was designed based on the rates of land conversion to agriculture as estimated by Houghton et al. (1982). Figure 2 (panel 1) displays the time evolution of the annual and hemispherical mean conversion of forests to grassland due to deforestation which was used in our simulations (hereafter referred to as VEG1). Note that the actual scenario is latitude and continent dependent but for reader's convenience only the hemispherical means are reproduced.

Besides man's impact on vegetation, it can also be anticipated that a vegetation-albedo-climate coupling should exist, since changing global climate produces modifications in large scale precipitation and temperature patterns which, in turn, modify the land vegetation and, hence, change the surface albedo, thus producing further climatic change. Therefore, we have also investigated the potential impact of the vegetation feedback on the surface temperature by running dynamically the vegetation model, i.e. without prescribing the land cover change (hereafter referred to as VEG2).

\subsection{Greenhouse gas forcing}

The Industrial Revolution (IR) is a key epoch for the release of greenhouse gases (GHG) in the

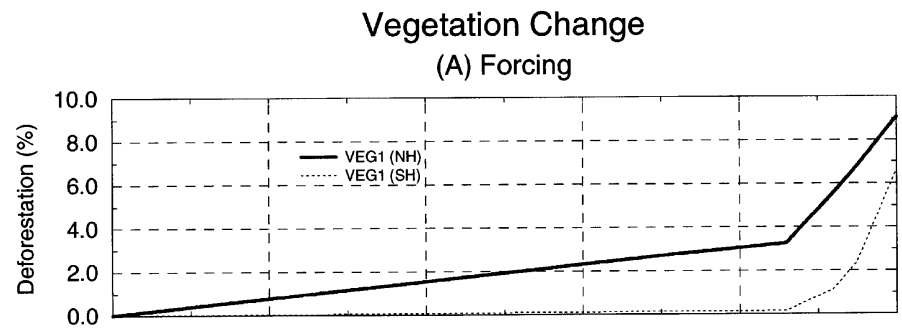

(B) Surface Temperature Responses

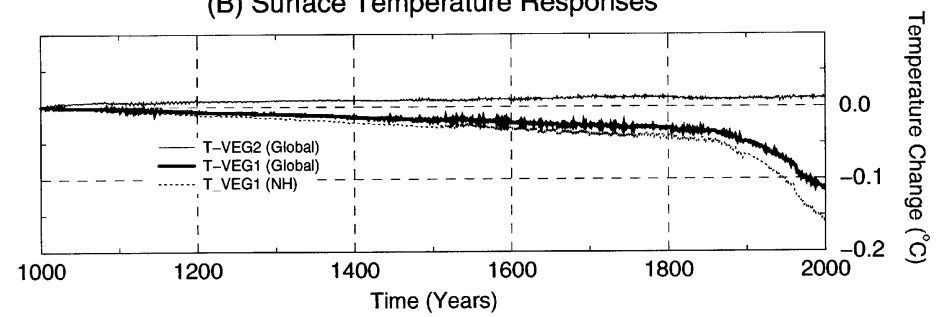

Fig. 2. Vegetation change and model responses. A.1 Time series of deforested continental fraction (VEG1) in the Northern (NH) and Southern (SH) hemisphere. A.2 Transient response of the averaged global and Northern hemisphere surface air temperature to vegetation change. T_VEG1 curves refer to deforestation while T_VEG2 curve provides the model response to the vegetation feedback driven by the orbital forcing only. Temperature anomalies are given relative to the equilibrium state.

Tellus 54A (2002), 3 
atmosphere. For several thousands of years before the beginning of IR, the atmospheric concentration of carbon dioxide remained close to 280 ppmv. This concentration has however increased substantially - by more than $30 \%$ since that time. Moreover, carbon dioxide is not the only GHG which has increased steadily in the atmosphere during the recent past. Several others have increased because of human activities (especially biomass burning, landfills, rice paddies, agriculture, animal husbandry, fossil fuel use and industry). They include methane, nitrous oxide, halocarbons, and tropospheric ozone, reinforcing the changes in radiative forcing from increased carbon dioxide.

The response of the Earth's climate to the concentration increase of these infrared-active gases in the atmosphere has been investigated using an effective- $\mathrm{CO}_{2}$ value (e.g. Tricot and Berger, 1987; Delobbe et al., 1997). Therefore, starting with the historical atmospheric $\mathrm{CO}_{2}$ concentration taken from Etheridge et al. (1996) and the $\mathrm{CH}_{4}$ concentration based on Nakazawa et al. (1993), we have calculated the equivalent $\mathrm{CO}_{2}$ concentration from the formulations given in Houghton et al. (1990, 1992, 1995). The time evolution of the atmospheric equivalent $\mathrm{CO}_{2}$ concentration over the past millennium is given in Fig. 3 (panel A.1) and compared to the Crowley's GHG time series. Due to the very close similarity between the two curves, we have not re-run our model with the Crowley's equivalent $\mathrm{CO}_{2}$ concentration.

However, taking advantage of the low computer cost of our model, model sensitivities to a doubling $\mathrm{CO}_{2}$ of 2.1 and $2.8^{\circ} \mathrm{C}$ have been considered. Note that these sensitivities are not prescribed in our model, but rather result from two different multilayer radiative schemes (for further informations see Delobbe et al., 1997). These sensitivities are in the lower range of the IPCC (Houghton et al., 1996) values for the equilibrium GCM simulations, but are close to the IPCC best estimate of $2.5^{\circ} \mathrm{C}$

\subsection{Anthropogenic aerosols forcing}

Beside the anthropogenic GHG forcing, anthropogenic aerosols exert also a radiative influence on climate (e.g. Charlson et al., 1991, 1992; Kiehl and Briegleb, 1993). Industrial activities, especially through emissions of $\mathrm{SO}_{2}$ from fossil-fuel combustion leading to the formation of particulate sulphate $\left(\mathrm{SO}_{4}^{2-}\right)$ contribute substantially to tropospheric aerosols, especially to submicrometer aerosols which are effective in the scattering of shortwave radiation. This aerosol is distributed quite nonuniformly over the Earth and its concentration has substantially increased since the Industrial Revolution.

The spatial and temporal distributions of those sulphate aerosols used in our transient climate simulations were generated from the monthly mean sulphate abundances simulated by the Moguntia model (Langner and Rodhe, 1991) corresponding both to the pre-industrial (1850, only natural sources) and industrial cases (1980, natural and anthropogenic sources). For the intermediate period we used an historical worldwide anthropogenic sulphur emission inventory recorded by Örn et al. (1996). Starting from the gridded (5x5 degree resolution) sulphur inventory, sulphur emissions trajectories were determined above each sector for each latitudinal band of our model. Such trajectories were then used to compute the sulphate concentration using a linear interpolation linking the two Moguntia sulphate concentration fields to the sulphur emission inventory. The estimated sulphur emissions over the industrial era are given in Fig. 3 (panel B.1). Note that prior to 1850 , the monthly mean sulphate abundances corresponding to the pre-industrial case have been used as background values.

In a number of previous transient climate simulations the direct effect of sulphate aerosol was represented by an increase in the clear sky surface albedo. Crowley (2000) introduced this forcing in his model runs by way of an hemispherical mean net radiative time series. In our experiments, the shortwave radiative flux perturbations were computed using the full radiative code. This code determines the optical properties of sulphate aerosols as function of sulphate concentration and relative humidity in each model layer and above each surface type (Bertrand and van Ypersele, 1997). In addition to the direct effect (scattering of sunlight radiation) sulphate aerosols particles act also as cloud condensation nuclei ( $\mathrm{CCN})$. The increase of these $\mathrm{CCN}$ may lead to more cloud droplets and hence to brighter clouds (Twomey, 1974). However, only the direct sulphate aerosol forcing has been taken into account in this study. 

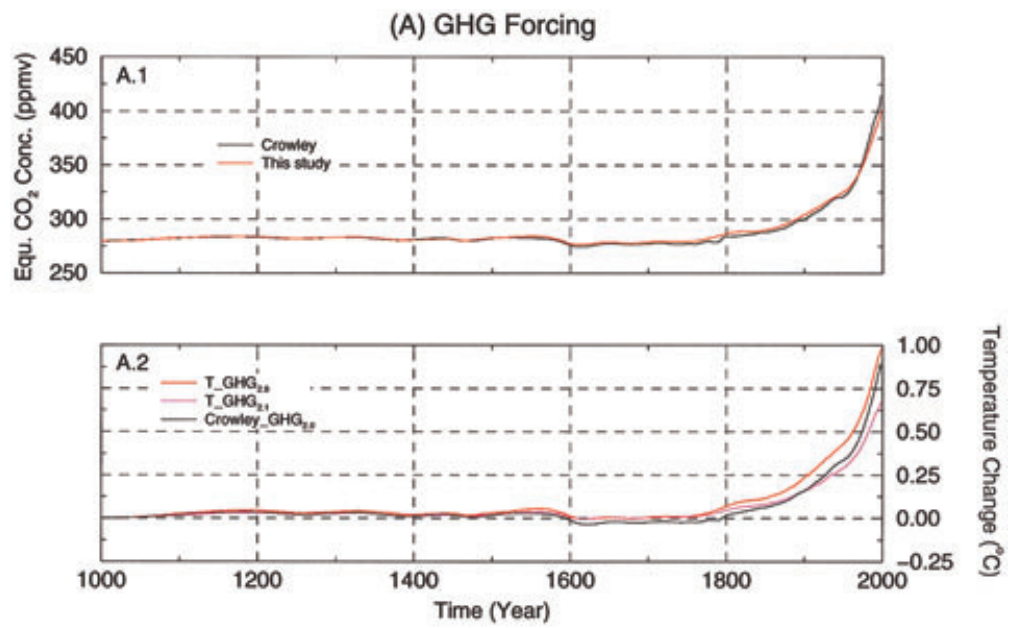

(B) Anthropogenic Sulphate Forcing
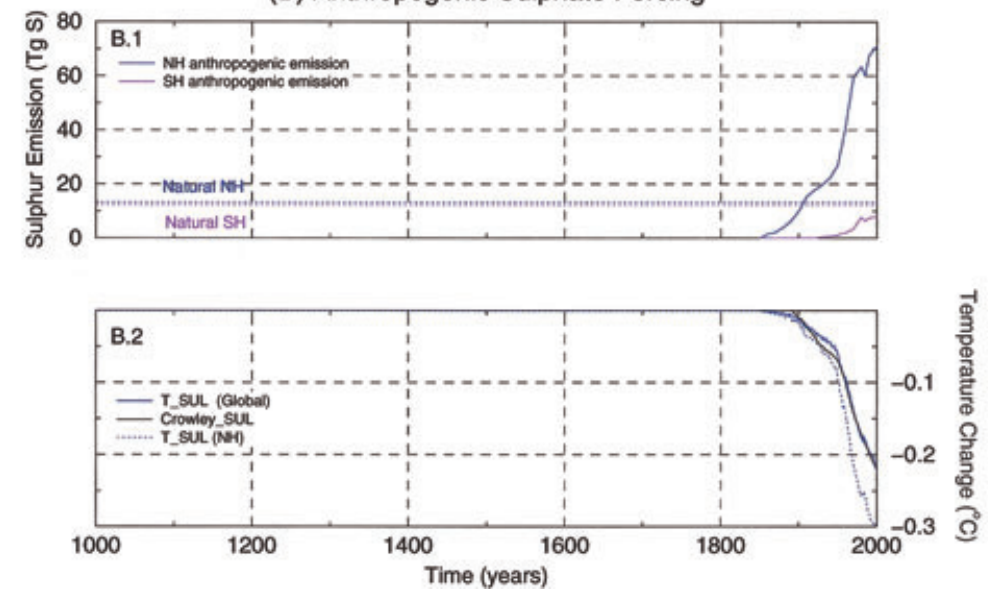

Fig. 3. Individual anthropogenic forcings and model responses. (A) GHG forcing: A.1 Comparison between the time evolution of the atmospheric equivalent $\mathrm{CO}_{2}$ concentration used in this sudy and in Crowley (2000). A.2 Transient response of the annual global mean surface air temperature to the GHG forcing. Subscripts 2.1 and 2.8 refer respectively to a sensitivity of 2.1 and $2.8^{\circ} \mathrm{C}$ for a doubling $\mathrm{CO}_{2}$ concentration. (B) Anthropogenic sulphate forcing: B.1 Estimated sulphur emissions over the past century (from Örn et al. 1996, updated). B.2 Transient response of the annual averaged global and Northern hemisphere surface air temperature to the direct sulphate forcing. Crowley model responses (2000) are provided for comparison (black curves in panels A.2 and B.2). Temperature anomalies are given relative to the equilibrium state.

\section{The experiments}

\subsection{Experimental setup}

Starting from the reconstructed 1000 AD forcing values, the model was first run until the seasonal cycle reached equilibrium. This equilibrium is assumed to be achieved when the annual global mean radiative balance at the top of the atmosphere varies by less than $0.01 \mathrm{~W} \mathrm{~m}^{-2}$ and that the annual global mean radiative balance at the surface of the ocean is less than $0.02 \mathrm{~W} \mathrm{~m}^{-2}$. This equilibrium takes more than 10000 years to be reached. Using this solution (including the vegetation distribution) as a new initial state, the model was then integrated from $1000 \mathrm{AD}$ to 1999 AD. The transient runs are performed with the different factors either $\mathrm{ON}$ or OFF (i.e. they

Tellus 54A (2002), 3 
were allowed to vary as described in the previous section or were kept fixed to their $1000 \mathrm{AD}$ equilibrium value). Due to the different climate forcing reconstructions and model sensitivities considered, a total of seventy-one climate simulations have been performed (see Tables 1 and 2 for some of them).

\subsection{Single factors}

The modeled responses to individual forcing terms are given in Figs. 1 to 3. In order to compare our model runs with the Crowley's model response, these figures display the transient response of the annual and global mean surface temperature to the considered forcing.

Table 1. Correlations for the pre-industrial interval 1000-1850 between model runs (Northern annual mean surface air temperature) and the CL2 (Crowley, 2000; Crowley and Lowery, 2000) and Mann (Mann et al., 1999) temperature time series, with the percentage of the variance explained shown in parentheses. Both the model responses and the reconstructed Northern annual mean temperature time series have been smoothed with a 11-year running mean procedure. Correlations have been subdivided into the following three categories. Top set: Correlations using the model response to individual natural climate forcings. Different abbreviations for solar (TSI) forcing refer to the different indices discussed in the text. TSI_R and TSI_L are from Bard et al. (2000) while TSI_Be10 is computed from Crowley (2000).VOL_Z refers to the volcanic forcing time series as computed from the Zielinski GISP2 record (Zielinski, 1995) and VOL_C to the volcanic time series reconstructed and used in Crowley (2000). Middle set: Correlations for model response to the combined natural forcing ( $N A T$ ' $=T S I+M I L+V O L)$ with and without including deforestation (VEG1). Bottom set: Correlations and explained variance for the model response to all combined forcings ('ALL') using a sensitivity of 2.1 ( $\left.A L L_{2.1}\right)$ or $2.8^{\circ} \mathrm{C}$ ( $A L L_{2.8}$ ) for a doubling $\mathrm{CO}_{2}$ concentration. When available, the Crowley's correlations (2000) are provided for comparison

\begin{tabular}{|c|c|c|}
\hline Simulation & CL2.11 & Mann.11 \\
\hline TSI_R & $0.18(03 \%)$ & $0.28(08 \%)$ \\
\hline TSI_L & $0.56(31 \%)$ & $0.52(27 \%)$ \\
\hline TSI_Be10 & $0.42(18 \%)$ & $0.44(19 \%)$ \\
\hline Crowley-TSI_Be10 & $0.42(18 \%)$ & $0.45(20 \%)$ \\
\hline VOL_Z & $0.28(08 \%)$ & $0.22(05 \%)$ \\
\hline VOL_C & $0.45(20 \%)$ & $0.45(20 \%)$ \\
\hline Crowley-VOL_C & $0.47(22 \%)$ & $0.48(23 \%)$ \\
\hline NAT $_{\text {VOL_Z }}$, TSI_R & $0.28(08 \%)$ & $0.35(12 \%)$ \\
\hline NAT $_{\text {VOL_Z, TSI_R, VEG1 }}$ & $0.36(13 \%)$ & $0.40(16 \%)$ \\
\hline NAT $_{\text {VOL_Z, TSI_L }}$ & $0.58(34 \%)$ & $0.50(25 \%)$ \\
\hline NAT $_{\text {VOL_Z, TSI_L, VEG1 }}$ & $0.65(42 \%)$ & $0.55(30 \%)$ \\
\hline NAT $_{\text {VOL_Z, TSI_Be10 }}$ & $0.39(15 \%)$ & $0.35(12 \%)$ \\
\hline NAT $_{\text {VOL_Z, TSI_Be10, VEG1 } 1}$ & $0.50(25 \%)$ & $0.42(18 \%)$ \\
\hline $\mathrm{NAT}_{\text {VOL_C }}$ TSI_R & $0.29(08 \%)$ & $0.39(16 \%)$ \\
\hline NAT $_{\text {VOL_C, TSI_R, VEG1 }}$ & $0.33(11 \%)$ & $0.42(18 \%)$ \\
\hline NAT $_{\text {VOL_C, TSI_L }}$ & $0.67(45 \%)$ & $0.64(40 \%)$ \\
\hline NAT $_{\text {VOL_C, TSI_L, VEG1 }}$ & $0.72(52 \%)$ & $0.66(43 \%)$ \\
\hline $\mathrm{NAT}_{\text {VOL_C, TSI_Be } 10}$ & $0.58(33 \%)$ & $0.57(33 \%)$ \\
\hline $\mathrm{NAT}_{\text {VOL_C, TSI_Be10, VEG1 } 1}$ & $0.63(39 \%)$ & $0.60(36 \%)$ \\
\hline Crowley-ALL 2.0 , voL_C, TSI_Be10 & $0.69(48 \%)$ & $0.64(41 \%)$ \\
\hline $\mathrm{ALL}_{2.1}$, VOL_C, TSI_R & $0.31(10 \%)$ & $0.40(16 \%)$ \\
\hline $\mathrm{ALL}_{2.1}$, vOL_C, TSI_R, VEG1 & $0.34(11 \%)$ & $0.39(15 \%)$ \\
\hline $\mathrm{ALL}_{2.1}$, vOL_C, TSI_L & $0.68(47 \%)$ & $0.63(40 \%)$ \\
\hline $\mathrm{ALL}_{2.1}$, vOL_C, TSI_L, vEG1 & $0.72(52 \%)$ & $0.65(42 \%)$ \\
\hline $\mathrm{ALL}_{2.1}$, VOL_C, TSI_Be10 & $0.61(37 \%)$ & $0.58(33 \%)$ \\
\hline $\mathrm{ALL}_{2.1}$, vOL_C, TSI_Be 10, VEG 1 & $0.66(44 \%)$ & $0.61(38 \%)$ \\
\hline
\end{tabular}


Table 2. Correlations and explained variance (shown in parentheses) over the entire time interval analyzed (1000-1999) between the model runs (11-point smoothed Northern annual mean air surface temperature) and the CL2 record spliced into the 11-point smoothed Jones et al. (1999) time series (CL2.Jns11) and the 11-point smoothed Mann et al (1999) time series (Mann.11). Correlations have been subdivided into the following three categories: Top set: Correlations for model responses to the combined natural forcing ( $N A T$ ' $=T S I+M I L+V O L$ ) deforestation (VEG1). Different abbreviations for solar (TSI) forcing refer to the different indices discussed in the text.TSI_R and TSI_L are from Bard et al. (2000) while TSI_Be10 is computed from Crowley (2000). VOL_C refers to the Crowley (2000) volcanic time series. Middle set: Correlations for model responses to anthropogenic forcing ( $A N T$ ' $=G H G+S U L)$. Subscripts 2.1 and 2.8 refer to a sensitivity of respectively 2.1 and $2.8^{\circ} \mathrm{C}$ for a doubled $\mathrm{CO}_{2}$ concentration. Bottom set: Correlations and explained variances for model responses to the combined natural and anthropogenic forcing ( $A L L '=$ $N A T+A N T)$. When available, the Crowley's correlation are provided for comparison

\begin{tabular}{|c|c|c|}
\hline Simulations & CL2.Jns11 & Mann.11 \\
\hline $\mathrm{NAT}_{\mathrm{TSI} \mathrm{R}}$ & $0.36(13 \%)$ & $0.43(19 \%)$ \\
\hline NAT $_{\text {TSI_R, VEG1 }}$ & $0.37(13 \%)$ & $0.43(19 \%)$ \\
\hline NAT $_{\text {TSI_L }}$ & $0.59(34 \%)$ & $0.52(27 \%)$ \\
\hline NAT $_{\text {TSI_L, VEG1 }}$ & $0.55(30 \%)$ & $0.45(20 \%)$ \\
\hline $\mathrm{NAT}_{\text {TSI_Be } 10}$ & $0.51(26 \%)$ & $0.47(22 \%)$ \\
\hline $\mathrm{NAT}_{\text {TSI_Be10, VEG1 }}$ & $0.45(21 \%)$ & $0.37(14 \%)$ \\
\hline $\mathrm{ANT}_{2.1}$ & $0.38(14 \%)$ & $0.45(20 \%)$ \\
\hline $\mathrm{ANT}_{2.1}, \mathrm{VEG} 1$ & $0.53(28 \%)$ & $0.53(28 \%)$ \\
\hline $\mathrm{ANT}_{2.8}$ & $0.40(16 \%)$ & $0.47(22 \%)$ \\
\hline $\mathrm{ANT}_{2.8, \mathrm{VEG} 1}$ & $0.48(23 \%)$ & $0.53(28 \%)$ \\
\hline $\mathrm{ALL}_{2.1}$, VOL_C, TSI_R & $0.38(15 \%)$ & $0.47(22 \%)$ \\
\hline $\mathrm{ALL}_{2.1}, \mathrm{VOL} \_\mathrm{C}, \mathrm{TSI} \mathrm{R}, \mathrm{VEG} 1$ & $0.40(16 \%)$ & $0.48(23 \%)$ \\
\hline $\mathrm{ALL}_{2.1}$, vOL_C $_{\text {, }}$ TSI_L & $0.66(44 \%)$ & $0.64(41 \%)$ \\
\hline $\mathrm{ALL}_{2.1}$, VOL_C, TSI_L, VEG1 & $0.68(46 \%)$ & $0.62(39 \%)$ \\
\hline $\mathrm{ALL}_{2.1}$, VOL_C, TSI_Be10 & $0.61(37 \%)$ & $0.61(37 \%)$ \\
\hline $\mathrm{ALL}_{2.1}$, VOL_C, TSI_Be 10, VEG1 & $0.63(40 \%)$ & $0.60(36 \%)$ \\
\hline Crowley-ALL 2.0 , vOL_C, TSI_Be10 & $0.66(43 \%)$ & $0.68(46 \%)$ \\
\hline $\mathrm{ALL}_{2.8}$, vOL_C, TSI_R & $0.41(17 \%)$ & $0.49(24 \%)$ \\
\hline $\mathrm{ALL}_{2.8}$, VOL_C, TSI_R, VEG1 & $0.43(19 \%)$ & $0.50(25 \%)$ \\
\hline $\mathrm{ALL}_{2.8}$, VOL_C, TSI_L & $0.66(44 \%)$ & $0.67(44 \%)$ \\
\hline $\mathrm{ALL}_{2.8}$, vOL_C, TSI_L, VEG1 & $0.70(49 \%)$ & $0.68(46 \%)$ \\
\hline $\mathrm{ALL}_{2.8}$, vOL_C, TSI_Be10 & $0.59(35 \%)$ & $0.62(39 \%)$ \\
\hline $\mathrm{ALL}_{2.8}$, vOL_C, TSI_Be10, VEG1 & $0.65(42 \%)$ & $0.65(42 \%)$ \\
\hline
\end{tabular}

While solar activity has risen systematically through the past four centuries, only the model response to the TSI variations scaled to the Reid's reconstruction, TSI_R, (see Fig. 1, panel A.2) exhibits a substantial net global warming (1999-1000 AD) of $0.53^{\circ} \mathrm{C}\left(0.62^{\circ}\right.$ for the Northern hemisphere). The model response to the TSI_Be10 leads to a net global warming of $0.12^{\circ} \mathrm{C}\left(0.14^{\circ} \mathrm{C}\right.$ in the Northern hemisphere), which compares well with the $0.11^{\circ} \mathrm{C}$ simulated by Crowley (2000). Finally, forcing the model with the TSI_L reconstruction provides a net global warming of $0.10^{\circ} \mathrm{C}$ $\left(0.12^{\circ} \mathrm{C}\right.$ in the Northern hemisphere) at the end of our simulation. Note that while the net global warming simulated in response to the TSI_Be10 time series is greater than the warming simulated with TSI_L, the maximum temperature variation simulated over the time period is smaller $(0.22 \mathrm{vs}$. $0.32^{\circ} \mathrm{C}$ in annual and global mean). Moreover the maximum temperature variation simulated in response to the TSI_R time series reaches more than $1^{\circ} \mathrm{C}$ in global mean. A detailed examination of Fig. 1 (panels A.1 and A.2) reveals that the air surface temperature response follows the solar output with a small time lag and that the simulated temperature variations are smoother than the 
variations of the forcings themselves. These two features are related to the large thermal inertia of the ocean which explains also a larger surface temperature response in the Northern hemisphere than in the Southern hemisphere (where the oceanic area is larger). Time series of the latitudinal distribution of the modelled surface temperature change (not shown) indicate that the largest temperature variations are located at high latitudes during both warming and cooling periods. This behaviour is related to the amplification of the climate response to the ice- and, to a lesser extent, to the snow albedo-temperature feedback. Clearly, the largest surface temperature response to the TSI forcing is at the centennial-scale of the Gleissberg cycle with peak-to-trough changes largely depending on the solar reconstruction; the influence of the 11-year Schwabe solar cycle is much less visible.

Variations in the orbital elements between 1000 and 1999 have generated a decrease in the hemispheric annual mean insolation received at the top of the atmosphere of around $0.0023 \mathrm{~W} \mathrm{~m}^{-2}$. The change can be larger for a particular month, e.g. the Northern (Southern) hemispheric mean incident solar radiation has increased by almost $4 \mathrm{~W} \mathrm{~m}^{-2}$ (3.5) in April (March) and decreased by roughly $4 \mathrm{~W} \mathrm{~m}^{-2}$ (4.5) in September (November). The impact of this forcing on the annual and global mean surface air temperature change remains nevertheless negligible at this time scale as clearly shown in Fig. 1 (panel A.2). As a consequence, our climate simulation does not support the suggestion by Mann et al. (1999) that the decrease in summer insolation could have contributed to the cooling between the Middle Age and the Little Ice Age. However, these changes are sufficient to introduce a slight difference between the annual global mean surface air temperature simulated in response to changes in the orbital parameters alone, and to the dynamical change in vegetation triggered by these insolation changes. Insolation variations are indeed sufficient to increase the number of growing degree-days above $0^{\circ} \mathrm{C}$ (the sum of temperature in degrees Celsius for days with surface air temperature above $0^{\circ} \mathrm{C}$ ), a major parameter for the modelled vegetation in the high latitudes which here increases the fraction of trees at these latitudes. In turn, this reduces the ground albedo, especially during the winter time when snow covers the continents, and leads to an increase of about $0.02^{\circ} \mathrm{C}$ in the annual global mean temperature. Such a warming is clearly too weak to be relevant, but illustrates the sensitivity of the model to the vegetation feedback.

The model response to the two historical volcanic forcing reconstructions is displayed in Fig. 1 (panel B.2) and compared with the Crowley's EBM response. The annual global mean surface air temperature response is characterized by a succession of coolings which can clearly be associated with coolings observed in the Mann et al. (1999) reconstruction (see Fig. 5A): e.g. the simulated cooling events in the mid 14 and 15th, in the late 16 , and early 17 th agree well with the temperature reconstruction. The comparison between panel B.1 and B. 2 on Fig. 1 shows that the temperature response follows the forcing closely, but the time for temperature to return to pre-perturbation is much longer than the time for the optical depth to recover in the volcanic experiments. This lag is related first to the heat capacity of the system and second to the amplification of the climate response by the snow and ice albedotemperature feedbacks and the water vapour-temperature feedback. Although the volcanic forcing is homogenously distributed through latitudes prior to 1850 for the VOL_Z reconstruction and prior to 1960 for the VOL_C time series, the largest temperature response occurs at high latitudes in both hemispheres (while the largest model response occurs in the Northern hemisphere).

Panel B.2 in Fig. 1 reveals a real discrepancy between our model response to VOL_C and the Crowley's one, especially concerning the amplitude of the simulated global mean air temperature. The magnitude of our model response is at least one third larger than the Crowley's one for a given volcanic event. Part of this difference could result directly from the net forcing used by Crowley. Let us remember that in order to force the EBM, Crowley converted the stratospheric aerosol optical depth into a net forcing using eq. (1). This equation is estimated to have an accuracy of about $25 \%$ for aerosol size distributions with an effective radius between 0.1 and $1 \mu \mathrm{m}$ (Lacis et al., 1992). Another difference between the two model results could arise from the models themselves, i.e. the representation of the different components of the climate system and the feedbacks between them. Crowley's confidence to the EBM results is based on a good agreement between the EBM and recent 
GCM studies of an averaged cooling at the decadal time scale resulting from volcanic activity during the late 20th century (Crowley, 2000). Such a decadal average procedure may be questionned due to the episodic nature of the volcanic perturbations, since it could largely smooth the difference between the coolings simulated by both models. On the other hand, our model certainly overestimates the surface temperature response due to a too crude representation of the interactions between the surface climate and the stratospheric dynamics which unables us to account for the winter warming associated to large volcanic eruptions, for example (e.g. Robock and Mao, 1992).

Deforestation (VEG1) is responsible for a discernible long term decrease in the annual global mean surface air temperature (see Fig. 2). This cooling reaches $0.11^{\circ} \mathrm{C}$ at the end of our simulation (a net cooling of $0.16^{\circ} \mathrm{C}$ being simulated in the Northern hemisphere). This cooling trend is mainly driven by deforestation in Northern hemisphere mid-latitudes, at least up to 1850 . After this date, the accelerated man-made land clearance increases the albedo in both hemispheres and causes a greater cooling rate. While deforestation started during the Middle Age, its impact on climate becomes more evident with time going on, and appears especially well marked over the last 150 years (Fig. 2, panel B).

Amongst the different single factor experiments, greenhouse gas forcing induces the largest warming (see Fig. 3A). Depending upon the model sensitivity to $\mathrm{CO}_{2}$ used, the simulated annual mean surface air temperature between $1000 \mathrm{AD}$ and 1999 increases by either $0.67^{\circ} \mathrm{C}\left(0.79^{\circ} \mathrm{C}\right)$ or $0.98^{\circ} \mathrm{C}$ $\left(1.17^{\circ} \mathrm{C}\right)$ on average for the whole globe (for the Northern hemisphere). Over the same time interval, the EBM used by Crowley simulates a net global warming of about $0.90^{\circ} \mathrm{C}$ with an equilibrium sensitivity of $2^{\circ} \mathrm{C}$ for a doubling of $\mathrm{CO}_{2}$. As highlighted by panel A.1 in Fig. 3, this difference of $0.2^{\circ} \mathrm{C}$ in magnitude between our $\mathrm{T}-\mathrm{GHG}_{2.1}$ simulation and the Crowley simulation (Crowley$\mathrm{GHG}_{2.0}$ ) can not be explained by the forcing itself. Moreover, the EBM temperature response starts to overtake our model response $\left(\mathrm{T}-\mathrm{GHG}_{2.1}\right.$ curve in Fig. 3 panel A.2) at the beginning of the twentieth century while the reconstructed equivalent $\mathrm{CO}_{2}$ concentration we use (panel A.1 in Fig. 3) remains a little bit larger than in Crowley up to 1965. We suspect that this is directly related to the ocean model and more specifically to the oceanic mixed-layer depth. Indeed, the transient temperature response to the GHG forcing simulated by the present version of our model is also much smaller than in Bertrand (1998) where the ocean model is an integral mixed-layer coupled to a diffusive deep ocean. We suggest that in a transient stage, the mixed-layer model warms the upper-ocean layer at an accelerated rate in comparison to a full ocean model and therefore, the warmer sea surface induces a larger response in this model.

Over the major part of our transient simulation (between 1000 and 1800 AD) the differences between the results obtained from the two sensitivities to a doubling $\mathrm{CO}_{2}$ concentration (i.e. 2.1 and $2.8^{\circ} \mathrm{C}$ ) are clearly negligible (Fig. 3, panel A.2). This is easily explained by the relatively low and stable atmospheric $\mathrm{CO}_{2}$ concentration over this period. After $1800 \mathrm{AD}$, the equivalent $\mathrm{CO}_{2}$ concentration progressively increases (mainly driven by $\mathrm{CO}_{2}$ release due to industrialization) until the end of the 1960s, and then accelerates. As we see in Fig. 3 (panel A.2), the difference between $\mathrm{T}-\mathrm{GHG}_{2.8}$ and $\mathrm{T}-\mathrm{GHG}_{2.1}$ reflects well this change in the atmospheric equivalent concentration with time.

The simulated response to the direct anthropogenic sulphate forcing (Fig. 3, panel B.2) illustrates clearly the differences between Northern hemisphere temperature and the global one. Indeed, the global mean response at the end of our simulation accounts only for $2 / 3$ of the Northern hemispheric mean response (a net cooling of $0.31^{\circ} \mathrm{C}$ instead of $0.22^{\circ} \mathrm{C}$ for the global mean). Because of the short atmospheric lifetime of the aerosols, their concentrations are largest near their sources. Hence, in contrast to the well-mixed GHG, they produce radiative forcings strongly latitudinally and sectorially differentiated. As a result, their impact on the Earth's surface temperature can be greater locally than globally. This is well highligthed in the time evolution of the zonally and sectorially averaged surface temperature simulated by the model (not shown). The direct sulphate aerosol forcing produces a most pronounced cooling over the Northern mid-latitude continental surfaces and the downwind oceanic sectors. However, it must be noted that, while the anthropogenic sulphate forcing is larger over the continental surfaces, an important cooling appears in 
the vicinity of the Northern sea-ice region. This is because the aerosol cooling is spread by the atmospheric circulation and amplified through the sea-ice feedback in the model. Similar cooling pattern is also found in more sophisticated climate models (e.g. Mitchell and Johns, 1997). In contrast to the GHG experiments, our model and Crowley's EBM both agree over a net global cooling of about $0.22^{\circ} \mathrm{C}$ at the end of simulation. This agreement might be due to the reduced magnitude of the global mean sulphate forcing when compared to the GHG one and to the fact that this forcing is mainly located over continal surfaces. These two factors make the larger sensitivity of the Crowley oceanic mixed-layer model less efficient.

This first series of sensitivity experiments reveals that only the greenhouse gas and the TSI forcings contribute to a long-term warming. Three other forcings (volcanism, deforestation, and anthropogenic sulfate aerosol) contribute to a long-term cooling, and finally, the impact of the change in the Earth's orbital elements as well as the dynamical change in vegetation have a negligible impact on the annual global mean surface temperature at this time scale. Moreover, none of these individual forcings appears to be sufficient to generate alone the reconstructed temperature time series. As an example, the model response to TSI underestimates the warming rate recorded over the past 150 years (except maybe the model response to TSI_R) and clearly the rapid warming after 1970 . By contrast, the response to GHG tends to overestimate the global warming trend.

\subsection{Natural forcings}

Figure 4 (panel A) shows that the joint effects of solar variability and volcanism could have contributed significantly to the general shape of temperature variations over the last millennium, including the Medieval Warm Period (11th to 13th century) and the Little Ice Age (1430-1890). It is worth pointing out that this figure displays the simulated variations of the annual mean Northern hemisphere surface air temperature rather than the global mean temperature as in Figs. 1 to 3. Indeed, we are now going to compare our model results to the reconstructed temperature time series. Let us remember that only the Northern hemisphere mean temperature (Fig. 5) has been reconstructed on an annual mean basis over the last millennium (Mann et al., 1999; Crowley and Lowery, 2000); but reconstructions of temperature during the warm season at midhigh latitudes are also available (Jones et al., 1998; Briffa, 2000).

When combining the natural forcings together, the model can account for up to $45 \%$ of the decadal-scale variance of the Northern hemisphere temperature over the pre-industrial period (from 1000 to 1850) (see for example the best correlation with Mann and Crowley obtained with NAT.VOL_C.TSI_L); the explained variance increasing up to $51 \%$ when including the impact of deforestation in our simulation as indicated in Table 1 (best correlation obtained with NAT.VOL_C.TSI_L.VEG1). By contrast, accounting for the vegetation feedback leads to a limited impact on the simulated annual mean Northern hemisphere temperature as illustrated in Fig. 4A (T-NAT.VOL_C.TSI_R.VEG2 is not different from T-NAT.VOL_C.TSI_R). Because the model does not simulate the interannual internal variability, the correlations are calculated over the smoothed time series using a 11-year running mean to emphasize the low frequency component of the response. Such correlations agree well with Crowley (2000) (although Crowley's correlations were performed between the simulated global mean temperature and reconstructed Northern hemisphere temperature time series). As shown in Table 1, the correlations for the interval $1000-1850$ vary substantially with the choice of the solar (TSI) reconstructions as well as of the volcanoes time series. Crowley stated that 22 to $23 \%$ of the decadal-scale variability can be explained by volcanism over the entire preanthropogenic interval, and up to 41 to $49 \%$ over the interval $1400-1850$, thereby indicating a very important role for volcanism during the Little age. Our results indicate however that the potential impact of volcanism on climate is greatly function of the volcanoes time series used in model simulations. Whatever only volcanic activity is used single or in combination with solar activity and/or vegetation, the Crowley reconstruction (VOL_C) leads to better results. When the model is forced with the Crowley's reconstruction of large volcanic eruptions over the last millennium (the VOL_C time series in Fig. 1) it can explain $20 \%$ of the Northern hemisphere decadal-scale temperature 
Last Millennium NH Surface Temperature Simulations (A) Natural Forcings Simulations

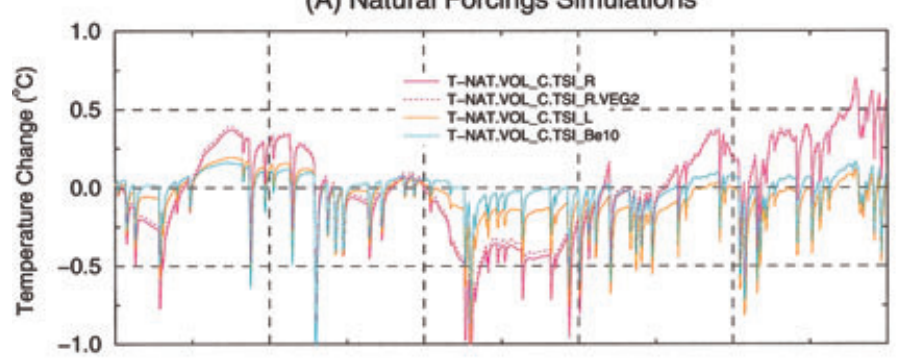

(B) Anthropogenic Forcings Simulations

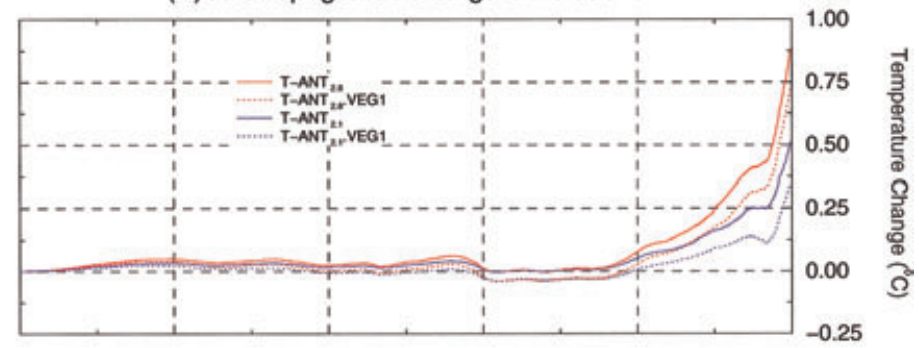

(C) All Combined Forcings Simulations

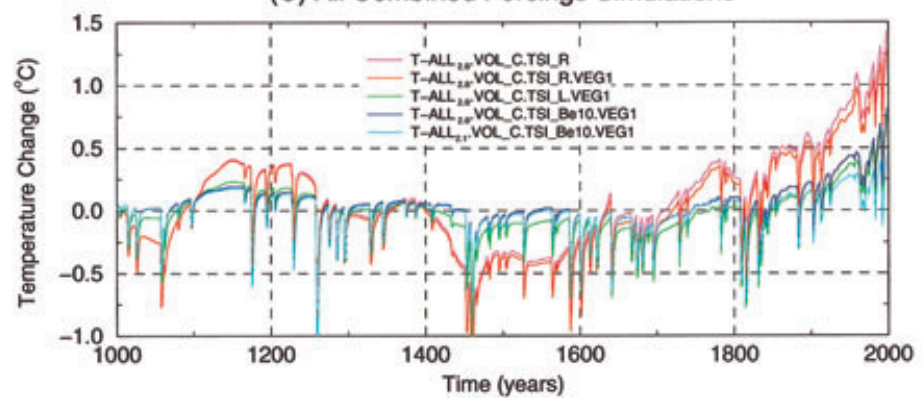

Fig. 4. Comparison between the annual mean Northern hemisphere surface air temperature response to (A) some natural forcings, (B) some anthropogenic forcings, and (C) all forcings over the past millennium. Different abbreviations for solar forcing (TSI_R, TSI_L, and TSI_Be10) refer to the solar indices discussed in the test. VEG1 refers to the deforestation while subscripts 2.1 and 2.8 inform on the sensitivity to a doubling $\mathrm{CO}_{2}$ concentration used.

variance over the pre-industrial interval and up to 36 to $42 \%$ over the time interval $1400-1850$. These results are similar to those of Crowley. However, the use of Zielinski GISP2 record (VOL_Z) largely reduced the potential impact of volcanism due to the reduced number of volcanic eruptions included in this time series.

Changes in the Sun's radiant energy output explain as low as 3\% (TSI_R time series) to as high as $31 \%$ (TSI_L time series) of the Northern hemisphere temperature variance over the preindustrial interval (1000-1850) (see Table 1).
$18-19 \%$ are explained when TSI_Be10 is used, similarly to the Crowley's results. Due to the difference in the magnitude of the irradiance changes from one TSI reconstruction to another, the Medieval Warm Epoch is simulated to be warmer than the Little Ice Age either by 0.2 (TSI_Be10 time series) or to about $0.75^{\circ} \mathrm{C}$ (TSI_R time series). Clearly, using the TSI_R solar time series leads to systematically overestimate the magnitude of the reconstructed temperature fluctuations over the pre-industrial interval while the TSI_Be10 time series tends to underestimate it; 


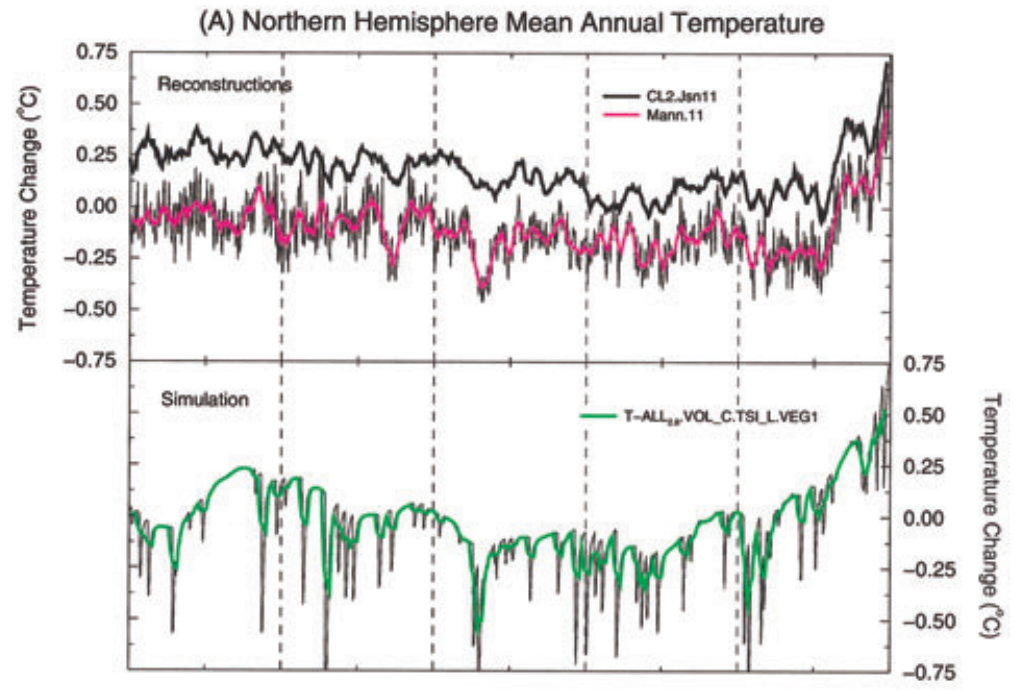

(B) Global and Annual Mean Temperature

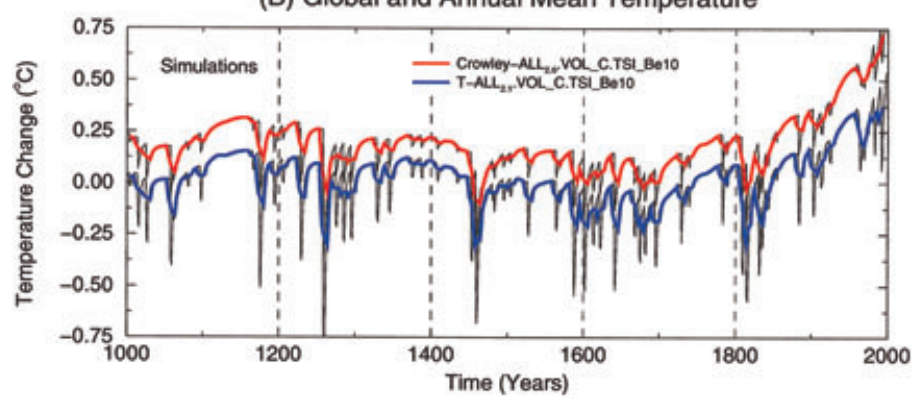

Fig. 5. (A) Comparison of simulated and reconstructed Northern hemisphere annual mean surface temperature. CL2.Jns11 is the Crowley and Lowery (2000) data set spliced into the 11-point smoothed Jones et al. (1999) Northern hemisphere instrumental record, with rescaling as discussed in Crowley (2000). Mann.11 refers to the 11-point smoothed Mann et al. (1999) time series. (B) Comparison of the annual global mean surface air temperature model responses to all forcings excepted vegetation change, simulated by the Crowley's EBM (2000) and by our model. In both panels, subscripts 2.8, 2.1, and 2.0 refer to the sensitivity for a doubling $\mathrm{CO}_{2}$ concentration while VOL_C and TSI_L or TSI_Be10 indicate the volcanic (VOL) or solar (TSI) reconstructions. VEG1 refers to the deforestation scenario.

the better Sun-climate correlations occurring with a long-term change in solar total irradiance scaled to the Lean et al. (1995) time series as reconstructed by Bard et al. (2000) from fluctuations of ${ }^{14} \mathrm{C}$ and ${ }^{10} \mathrm{Be}$.

Recorded Northern hemisphere annual mean surface temperature exhibits a linear warming trend of about $0.45^{\circ} \mathrm{C} /$ century over the last 150 years. By contrast, simulated Northern hemisphere surface temperature only accounts for a linear warming rate ranging from 0.0 to $0.17^{\circ} \mathrm{C} /$ century in response to the combined solar and volcanic (VOL_C) forcings. Therefore, while the externallydriven natural climate forcings could have modulated the evolution of the Earth's temperature in a non-negligible way over the pre-industrial times, changes in solar and volcanic activities appear to be too weak to explain the warming which occurs since the second half of the 19th century. Even when using TSI_R, the model fails to reproduce 
the accelerated warming which started after 1970 (see Fig. 5). Finally, over the entire time interval (1000-1999) 13 to $34 \%$ of the decadal-scale temperature variations could be attributed to externally driven natural variability depending whether TSI_R or TSI_L is used.

\subsection{Anthropogenic forcings}

Figure 4B shows that the forcing by GHG is not significant before 1800 , although there is a cooling phase (a net temperature drop of about $0.06^{\circ} \mathrm{C}$ ) in the 17 th and 18 th centuries that reflects the $\mathrm{CO}_{2}$ decrease in the original ice core record (Etheridge et al., 1996). This temperature drop associated with the long-term cooling trend generated by deforestation in mid-latitudes of the Northern hemisphere is however sufficient to increase the explained Northern temperature decadal-scale variance up to $52 \%$ (see NAT.VOL_C.TSI_L.VEG1 Table 1) over the preindustrial era (1000 to $1850 \mathrm{AD})$. The long-term cooling induced by vegetation changes allows to reinforce the Little Ice Age period and to delay some extent the warming trend generated in our natural forcings simulations (Fig. 4A) during the 19th.

If the influence of the GHG forcing appears to be limited during the pre-industrial interval, it is however essential for generating the twentieth century global warming. Figure 4B indicates that the simulations using the anthropogenic forcings only reproduce well the warming of the last decades, but underestimate the early 20th century warming by a factor of about 2 when the high sensitivity to $\mathrm{CO}_{2}$ is used, and by a factor of 4 when using the low sensitivity to $\mathrm{CO}_{2}$. Accordingly, the simulated anthropogenic linear warming trends over the past 150 years, ranging from 0.13 to $0.39^{\circ} \mathrm{C} /$ century, underestimate the recorded ones.

Statistical analysis of global temperature trends from 1861 to 1987 have revealed that, while temperature has increased in both hemispheres, there has been a pronounced decrease in the Northern hemisphere temperatures between 1940 and 1970, which did not occur in the Southern hemisphere (Jones et al., 1986; Jones, 1988). As shown in Fig. 4B, anthropogenic forcings simulations capture, at least partly, this slight cooling in the Northern hemisphere. Part of it could be attrib- uted to the anthropogenic sulphate forcing which predominantly affects the Northern hemisphere (because of their short atmospheric lifetime, aerosol concentrations are the largest near their sources). This period (1940-1970) coincides with a time when sulphur emissions exceeded the natural level in Northern hemisphere and grew rapidly before emission controls. However, while the aerosol increase introduces a break in the Northern hemisphere warming, the slight cooling can only be simulated if deforestation is included. Indeed, only the simulation accounting for the low sensitivity to $\mathrm{CO}_{2}$ and deforestation presents a cooling trend over the period 1940 to 1970 , while the other simulations lead to a decrease in the warming rate or to a stable temperature. It is however possible to simulate a longer period over which temperature remains constant or a more pronounced cooling trend if part of the sulphate particles in each model layer were allowed to play a role in the indirect sulphate forcing rather than assuming that all sulphate particles act in the direct sulphate forcing as it is presently done. The rapid warming after 1970 is the response to an accelerated greenhouse intensification and a slower rate of cooling from sulphate aerosols and deforestation. These model results suggest that the global warming accelerates as soon as the greenhouse intensification begins to dominate over the combined effect of the anthropogenic sulphate aerosols and land surface changes.

\subsection{All the forcings}

Whatever the model sensitivity to a doubling $\mathrm{CO}_{2}$ concentration, the TSI reconstruction, and the change in vegetation, neither an individual forcing nor any combinations of natural or of anthropogenic forcings allow to simulate correctly the Northern hemisphere temperature fluctuations over the last millennium. Combining all forcings (Fig. 4C) results in a much better agreement between simulations and reconstructions. However, due to incertainties in both the forcings and the temperature reconstructions, the modeldata correlation is largely depending on the forcing reconstructions and on the combinations used to force the model, as highlighted in Table 2. All the forcings (solar, volcanism, vegetation change, tropospheric sulphate aerosols, and GHG) explain from 15 to $50 \%$ of the smoothed Northern hemi- 
sphere mean surface air temperature variations over the entire records. The highest correlation is obtained when forcing the model with TSI_L and using a sensitivity of $2.8^{\circ} \mathrm{C}$ for a doubling of $\mathrm{CO}_{2}$. Fig. 5A clearly indicates some striking correspondences between the model and the data over the whole past 1000 years.

Applying the multi-taper Thompson spectral analysis method (MTM) (Thomson, 1982, 1990) to both the best guess simulation and the reconstructions produces similar spectra. Periods significant above the $95 \%$ level in our simulation $\mathrm{ALL}_{2.8}$.VOL_C.TSI_R.VEG1 are 182, 71.5, 46.4, 27.6, 22.1, 14.2, $11.7 \quad 10.6$ and 10.1 years (Fig. 6. B.ii). These are pretty close to the periods found in Mann et al. (1999) (Fig. 6. A.ii) and also in the Crowley and Lowery (2000) rescaled times series (Crowley, 2000) where we find 176.2, 69.7, $48.6,37.3,35.3,19.5,17.7,13.8,12.8$, and 10.7 years.

However, while our simulations capture part of the low frequencies of the past millennium Northern hemisphere temperature records, there are also disagreements between the model results and the reconstructions, as from 1830 to 1920 . During this period, the simulated temperatures are systematically warmer than the recorded ones. In our best guest simulation (Fig. 5A) the difference can reach up to about $0.2^{\circ} \mathrm{C}$. As previously reported by Crowley (2000) and shown in Fig. 4C, this gap between the model results and the data is independent of the solar forcing reconstruction. Crowley (2000) suggested two factors that could contribute to the model-data differences over this interval: (i) mid-latitude land clearance, and (ii) sparse data coverage in the early stage of the instrumental record. Including deforestation in our simulations indicates however that this factor is unsufficient to explain the model-data discrepancy, although it reduces the simulated warming trend. Our results would therefore support the second suggestion by Crowley, although such differences could simply result from uncertainties in the paleo reconstructions or in the forcings. Nevertheless, the general agreement between the observed and the simulated smoothed temperature variations strongly supports the idea that the anthropogenic forcings, modulated by variations in solar and volcanic activities, is the main driver of climate change during the past century.

Finally, the model-data correlations reported in Tables 1 and 2 are slightly lower than those computed by Crowley: his maximum reaches $59 \%$ over the entire length of the records against slightly less than $50 \%$ in our simulation $\mathrm{ALL}_{2.8}$.VOL_C.TSI_L.VEG1. Nevertheless, when using our simulated annual global mean temperature, as Crowley does, rather than the Northern hemisphere mean annual temperature, our explained variance slightly increases. For example, the correlation between ALL $_{2.1}$.VOL_C.TSI_Be10 and the Mann et al. (1999) reconstruction is enhanced from 0.61 (Table 2) to 0.65 when our simulated annual global mean temperature is used, this value being closer to Crowley (2000) for a similar experiment $(0.66$ for Crowley$\mathrm{ALL}_{2.0}$.VOL_C.TSI_Be10 in Table 2).

Figure 5B provides finally a comparison between the annual global mean surface air temperatures simulated by our model and by the Crowley's EBM model when both are forced by all similar forcings over the past millennium. This illustrates well the main differences already pointed out: (i) our larger model response to volcanic activity, and (ii) a warming rate larger in Crowley than in our model in response to the GHG forcing using almost the same $\mathrm{CO}_{2}$ sensitivity.

\section{Final discussion and conclusions}

A two-dimensional sector-averaged global climate model has been used to investigate systematically the relative effects of externally driven natural and anthropogenic forcings on the climate of the last millennium. Simulations were based on reconstructions of the main anthropogenic and natural external forcings. The anthropogenic forcings include greenhouse gases, sulphate aerosols from the industry and deforestation. The natural forcings are related to changes in the amount of stratospheric aerosols following large volcanic eruptions, and to modifications in solar radiation (related to the periodic changes in the Earth's orbital elements as well as to the energy output of the Sun itself).

When all the natural and anthropogenic forcings are taken into account, the model successfully simulates the major annual mean Northern hemisphere surface air temperature variations over the last millennium. Simulations show a 'Medieval Warm Period' in the interval $1000-1300$ with a maximum in the 12 th to 13 th, a transition interval 
(A) Reconstruction: Mann et al. (i) MTM amplitudes

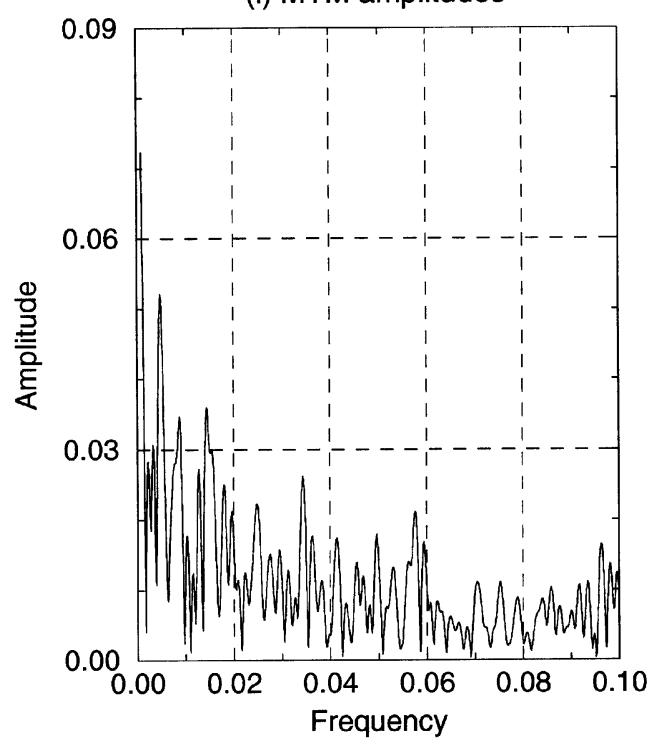

(ii) MTM F-test values

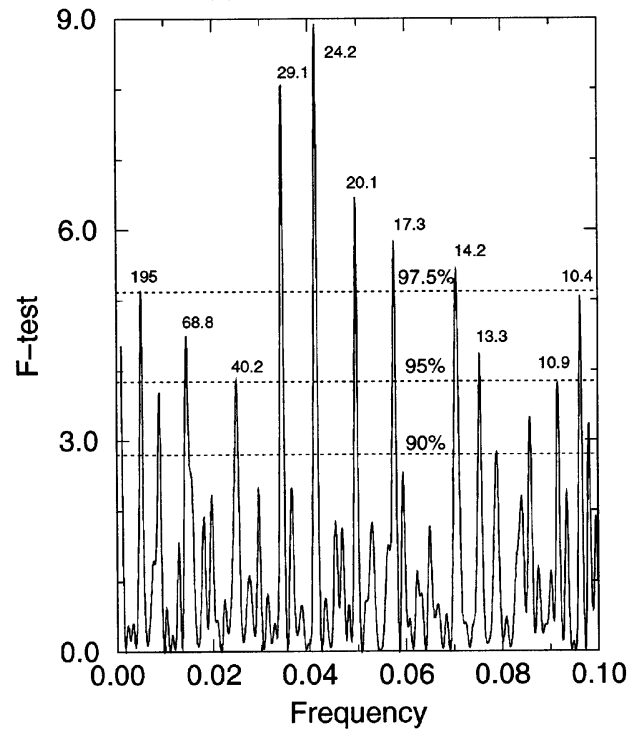

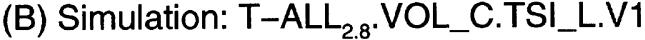
(i) MTM amplitudes

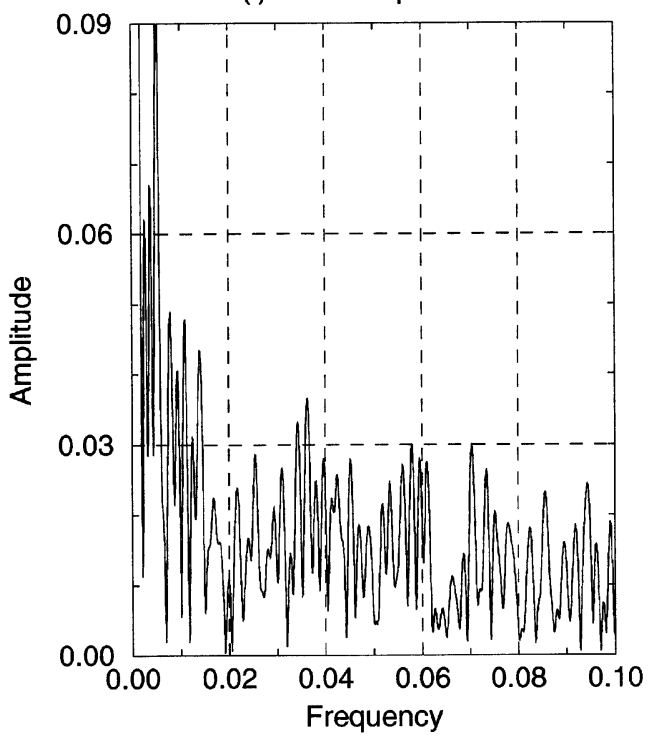

(ii) MTM F-test values

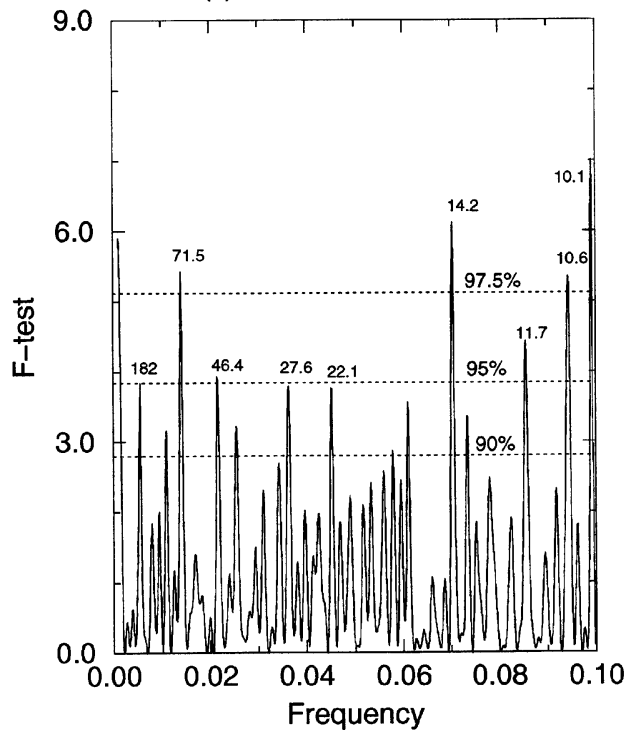

Fig. 6. Multi-taper Thompson (MTM) spectral analysis of the 1000 years long (1000-1999) Northern hemisphere mean annual surface temperature reconstruction by (A) Mann et al (1998) and our best guess simulation (B). The top panels give the amplitude of the detected cycles and the bottom panels the corresponding F-test values. The periods significant at the $95 \%$ level are quoted. 
from about 1300 to 1450 , a long colder period often termed the 'Little Ice Age', the 18th century recovery, and a cold period in the early 19th century. The approximately $0.2^{\circ} \mathrm{C} /$ decade rate of warming that is observed over the last three decades is also reproduced by the model, and both simulations and observations show a similar rate of warming between 1910 and 1939. It must be stressed that these results were obtained without any retuning of the climate model between the pre-industrial and the industrial experiments. The agreement between the reconstructed and simulated decadal-scale temperature variations strongly supports the range of total solar irradiance variations proposed by Lean et al. (1995). Reconstruction of the volcanic activity from Greenland Ice Sheet Project 2 (Zielinski, 1995) underestimates the impact of volcanism over the last millennium since a number of large volcanic eruptions are not present in this time series. Moreover the model results suggest that a sensitivity of $2.8^{\circ} \mathrm{C}$ for a double $\mathrm{CO}_{2}$-concentration is more consistent with the reconstructions than a sensitivity of $2.1^{\circ} \mathrm{C}$, although this could be a model-dependent result.

While combinations of natural forcings produce a gradual warming up to about 1960, none of them leads to a warming over the last 30 years (this period containing three major volcanic eruptions). In contrast, simulations incorporating only anthropogenic forcings reproduce the warming over the last three decades at a rate consistent with that observed, but underestimate the early 20 th century warming. As a consequence, only the use of both natural and anthropogenic forcings allows to reproduce much of the observed decadal scale variations of the annual mean hemispheric temperature over the last 150 years.

Before the industrial revolution, the combination of solar variability and volcanic eruptions explains the major temperature fluctuations as the Medieval solar warming, the large cooling in the Little Ice Age, the 18th century recovery, and the cold period in the early 19th century. While the impact of deforestation appears to be really significant over the last 150 years, accounting for mid-latitude land clearance also reinforces the Little Ice Age in our simulations. It reduces also the difference between the model results and the data between 1830 and 1920, a period over which the simulated temperatures are systematically larger than the recorded ones. It remains however that some differences are left, suggesting that the warming may have been underestimated in the early stage of the instrumental record because of sparse data coverage.

Although it is difficult to achieve attribution of all or part of a climate change to a specific cause using global mean temperature changes only (Houghton et al., 1996), our results suggest that there is an anthropogenic component in the past 150 years of the temperature record. One of the difficulties to validate the simulations over the last millennium arises however from the uncertainties in the history and magnitudes of the natural and human-induced climate forcings, so that many possible forcing combinations could yield almost same curve of global mean temperature change. Moreover, our simulations account only for the direct forcing of the anthropogenic sulphate particles and neglect changes in stratospheric ozone and other potentially large sources of natural and anthropogenic aerosols such as those associated to large-scale land-use changes (Tegen and Fung, 1995) and the carbonaceous aerosols generated by biomass burning (Penner et al., 1992, 1994).

Although our climate model does not have internal variability (e.g. the model reaches a steady equilibrium in response to time-independent forcing), we do not think that this will modify significantly our main results. Stouffer et al. (1994) have indeed found from a 1000-year long integration made with a coupled three-dimensional model that for intervals longer than about 60 years, there are no trend as large as $0.5^{\circ} \mathrm{C} /$ century. This implies that it is unlikely that the ocean-atmosphere-land interactions would randomly generate a substantial long-term warming trend, such as that observed since the end of the last century and simulated here.

Finally, it is expected that the large number of sensitivity experiments done in this paper will help general circulation models to select some forcings for which the validity of our results would be tested, the model used here being only of reduced complexity.

\section{Acknowledgements}

We would like to thank $H$. Rodhe and U. Hansson for having provided the data from the 
MOGUNTIA model and for the anthropogenic sulphur emission data set, and E. Bard and G. Raisbeck for their TSI reconstructions. This research was partly funded by the Impulse Programme 'Global Change' (Contract GC/DD/13, Belgian State, Prime Minister's Office,
Federal Office for Scientific, Technical and Cultural Affairs). Cédric Bertrand is scientific research worker and Michel Crucifix research fellow with the Belgium National Fund for Scientific Research.

\section{REFERENCES}

Bard, E., Raisbeck, G., Yiou, F. and Jouzel, J., 1997. Solar modulation of cosmogenic nuclide production over the last millenium: comparison between ${ }^{14} \mathrm{C}$ and ${ }^{10}$ Be records. Earth Planet. Sci. Lett. 150, 453-462.

Bard, E., Raisbeck, G., Yiou, F. and Jouzel, J. 2000. Solar irradiance during the last $1200 \mathrm{yr}$ based on cosmogenic nuclides. Tellus 52B, 985-992.

Barnett, T. P., Hasselman, K., Chelliah, M., Delworth, T., Hergerl, G., Jones, Ph., Rasmusson, E., Roecker, E., Ropelewski, C., Santer, B. and Tett, S. 1999. Detection and attribution of recent climate change: a status report. Bull. Amer. Meteorol. Soc. 80(12), 2631-2659.

Berger, A. 1978. Long-term variations of daily insolation and quaternary climatic changes. J. Atmos. Sci. 35, 2362-2367.

Berlyand, T. G. and Strokina, L. A. 1980. Zonal cloud distribution on the Earth. Meteorol. Gidrol. 3, 15-30.

Bertrand, C. 1998. Climate simulation at the secular time scale. Ph.D. thesis, 208 pp., Institut d'Astronomie et de Géophysique Georges Lemaître, Université catholique de Louvain, Louvain-la-Neuve, Belgium.

Bertrand, C. and van Ypersele, J.-P. 1997. Effects of relative humidity and temperature on sulphate aerosol optical properties. Beitr. Phys. Atmosph. 70, 233-243.

Bertrand, C. and van Ypersele, J.-P. 1999. Potential role of solar variability as an agent for climate change. Clim. Change 43, 387-411.

Bertrand, C., van Ypersele, J.-P. and Berger, A. 1999. Volcanic and solar impacts on climate since 1700 . Climate Dyn. 15, 355-367.

Briffa, K. R. 2000. Annual climate variability in the Holocene: interpreting the message of ancient trees. Quat. Sci. Rev. 19, 87-105.

Broecker, W. S. 2001. Was the medieval warm period global? Science 291, 1497-1499.

Brokvin, V., Ganopolski, A. and Svirezhev, Y. 1997. A continuous climate-vegetation classification for use in climate-biosphere studies. Ecoll. Modell. 101, 251-261.

Brovkin, V., Ganopolski, A., Claussen, M., Kubatzki, C. and Petoukhov, V. 1999. Modelling climate response to historical land cover change. Global Ecology and Biogeography 8, 509-517.

Bryan, K. 1969. A numerical method for the study of the circulation of the World Ocean. J. Comp. Phys. 4 347-346.

Campin, J.-M. and Goosse, H. 1999. Parameterization of density-driven downsloping flow for a coarse- resolution ocean model in $z$-coordinate. Tellus $\mathbf{5 1 A}$, 412-430.

Charlson, R. J., Langner, J., Rodhe, H., Levoy, C. B. and Warren, S. G. 1991. Perturbation of the northern hemisphere radiative balance by backscattering from anthropogenic sulfate aerosols. Tellus 43AB, 152-163.

Charlson, R. J., Schwartz, S. E., Hales, J. M., Cess, R. D., Coakley, J. A., Hansen, J. E. and Hofmann, D. J. 1992. Climate forcing by anthropogenic aerosols. Science 255, 423-430.

Crowley, T. J. 2000. Causes of climate change over the past 1000 years. Science $\mathbf{2 8 9}, \mathbf{2 7 0 - 2 7 7 .}$

Crowley, T. J. and Kim, K.-Y. 1999. Modeling the temperature response to forced climate over the last six centuries. Geophys. Res. Lett. 26, 1901-1904.

Crowley, T. J. and Lowery, T. S. 2000. How warm was the medieval warm period? Ambio 29, 51-54.

Crucifix, M., Tulkens, Ph. and Berger, A. 2001. Modelling abrupt climatic change during the last glaciation. In: The oceans and rapid climate change: past, present and future, vol. 126 of AGU Monograph Series, Americain Geophysical Union (in press).

Cubasch, U., Voss, R., Hegerl, G. C., Waszkewitz, J. and Crowley, T. J. 1997. Simulation of the influence of solar radiation variations on the global climate with an ocean-atmosphere general circulation model. Climate Dyn. 13, 757-767.

Delobbe, L., Tricot, Ch. and van Ypersele, J.-P. 1997. Tropopause-height feedback and radiative forcing in 2D climate simulations. Atmósfera 10, 75-99.

Etheridge, D. M., Langenfelds, R. L., Francey, R. J., Barnola, J.-M. and Morgan, V. I. 1996. Natural and antropogenic changes in atmospheric $\mathrm{CO}_{2}$ over the last 1000 years from air in Antarctic ice and firn. J. Geophys. Res. 101, 4115-4128.

Franklin, B. 1784. Meteorological imaginations and conjectures, Paper read 22 December 1784 to Literary and Philosphical Society of Manchester, reprinted by Sigurdsson (1982)

Free, M. and Robock, A. 1999. Global warming in the context of the Little Ice Age. J. Geophys. Res. 104, 19,057-19,070.

Gallée, H., van Ypersele, J.-P., Fichefet, Th., Tricot, Ch. and Berger, A. 1991. Simulation of the last glacial cycle by a coupled, sectorially averaged climate-ice sheet model I. The climate model. J. Geophys. Res. 96 13,139-13,163.

Gallée, H., van Ypersele, J.-P., Fichefet, Th., Marsiat, I.,

Tellus 54A (2002), 3 
Tricot, Ch. and Berger, A. 1992. Simulation of the last glacial cycle by a coupled, sectorially averaged climate-ice sheet model II. Response to insolation and $\mathrm{CO}_{2}$ variation. J. Geophys. Res. 97, 15,713-15,740.

Goosse, H. and Fichefet, Th. 2000. Open-ocean convection and polynya formation in large-scale ice-ocean model. Tellus 53A, 94-111.

Gregory, J. M. and Mitchell, J. F. B. 1997. The climate response to $\mathrm{CO}_{2}$ of the Hadley Centre coupled AOGCM with and without flux adjustment. Geophys. Res. Lett. 24, 1943-1946.

Hammer, C. U., Clausen, H. B. and Dansgaard, W. 1980. Greenland ice sheet evidence of post glacial volcanism and its climatic impact. Nature 288, 230-235.

Hansen, J. E., Wang, W. C. and Lacis, A. A. 1978. Mount Agung provides a test of a global climatic perturbation. Science 199, 1065-1068.

Hansen, J. E., Lacis, A. A., Lee, P. and Wang, W. C. 1980. Climatic effects of atmospheric aerosols. Ann New York Acad. Sci. 338, 575-587.

Harshvardhan, 1979. Perturbations of the zonal radiation balance by stratospheric aerosol layer. J. Atmos. Sci. 36, 1274-1285.

Harvey, L. D. 1986. A three-level energy balance climate model with topography, explicit radiative transfer, and explicit sea ice and snow mass budgets. Ph.D. thesis, 333 pp., University of Toronto, Toronto, Ont., Canada

Harvey, L. D. 1988. Development of a sea-ice model for use in zonally averaged energy balance models. J. Climate 1, 1221-1238.

Harvey, L. D. 1992. A two-dimensional ocean model for long-term climatic simulations: stability and coupling to atmospheric and sea-ice models. J. Geophys. Res. 97, 9435-9453.

Hergerl, G., von Storch, H., Hasselman, K., Santer, B. D., Cubasch, U. and Jones, P. D. 1996. Detecting anthropogenic climate change with a fingerprint method. J. Climate 9, 2281-2306.

Hegerl, G. C., Hasselmann, K., Cubasch, U., Mitchell, J. F. B., Roeckner, E., Voss, R. and Waszkewitz, J. 1997. Multi-fingerprint detection and attribution analysis of greenhouse gas, greenhouse gas-plus-aerosol and solar forced climate change. Clim. Dyn. 13, 613-634.

Holton, J. R. 1979. An introduction to dynamic meteorology. Academic Press, San Diego, CA, USA, 314 pp.

Houghton, R. A., Hobbie, J. E., Melillo, J. M., Moore, B., Peterson, B. J., Shaver, G. R. and Woodwell, G. M. 1982. Changes in carbon content of terrestrial biota and soils between 1860 and 1980: a net release of $\mathrm{CO}_{2}$ to the atmosphere. Ecological Monographs 53, $235-262$.

Houghton, J. T., Jenkins, G. J. and Ephraums, J. J. 1990. Climate change: the IPCC scientific assessment. Cambridge University Press, Cambridge, UK, $365 \mathrm{pp}$.

Houghton, J. T., Callander, B. A. and Varney, S. K. 1992. Climate change 1992: the supplementary report to the IPCC scientific assessment. Cambridge University Press, Cambridge, UK, 198 pp.

Houghton, J. T., Meira Filho, L. G., Bruce, J., Hoesung
Lee, Callander, B. A., Haites, E. F., Harris, N. and Maskell, K. 1995. Climate change 1994: radiative forcing of climate change and an evaluation of the IPCC IS92 emission scenarios. Cambridge University Press, Cambridge, UK, 339 pp.

Houghton, J. T., Meira Filho, L. G., Callander, B. A., Harris, N., Kattenberg, A. and Maskell, K. 1996 Climate change 1995: the science of climate change. Cambridge University Press, Cambridge, 572 pp.

Hovine, S. and Fichefet, T. 1994. A zonally averaged, three-basin ocean circulation model for climate studies. Clim. Dyn. 10, 313-331.

Jaeger, L. 1976. Monatskarten des nierderschlags für die ganze erde. Tech. Rep. 139, Ber. Dtsch. Wetterdienstes, $38 \mathrm{pp}$.

Jones, P. D. 1988. The influence of ENSO on global temperatures. Climate Monitor 17, 80-89.

Jones, P. D., Raper, S. C. B. and Wigley, T. M. L. 1986. Southern hemisphere surface air temperature variations: 1851-1984. J. Clim. Appl. Meteorol. 25, 1213-1230.

Jones, P. D., Briffa, K. R., Barnett, T. P. and Tett, S. F. B 1998. High-resolution paleoclimatic records for the last millennium: interpretation, integration and comparison with general circulation model control-run temperatures. The Holocene 8, 455-471.

Jones, P. D., New, M., Parker, D. E., Martin, S. and Rigor, I. G. 1999. surface air temperature and its changes over the past 150 years. Rev. Geophys. 37, 173-199.

Kiehl, J. T. and Briegleb, B. P. 1993. The relative roles of sulfate aerosols and greenhouse gases in climate forcing. Science 260, 311-314.

Kim, K.-Y. and Crowley, T. J. 1994. Modeling the climate effect of unrestricted greenhouse emissions over the next 10,000 years. Geophys. Res. Lett. 21, 681-684.

Lal, D. and Peters, B. 1967. Cosmic ray produced radioactivity on the Earth. In: Handbuch der Physik, XLVI/ 2, Springer, Berlin, 551-612.

Lacis, A., Hansen, J. and Sato, M. 1992. Climate forcing by stratospheric aerosols. Geophys. Res. Lett. 19, 1607-1610.

Lamb, H. H. 1970. Volcanic dust in the atmosphere; with a chronology and assessment of its meteorological significance. Phil. Trans. Roy. Soc. London A 226, $425-533$.

Langner, J. and Rodhe, H. 1991. A global three-dimensional model of the tropospheric sulphur cycle. J. Atmos. Chem. 13, 225-263.

Langway Jr., C. C., Osada, K., Clausen, H. B., Hammer, C. U. and Shoji, H. 1995. A 10th century comparison of prominent bipolar volcanic events in ice cores. J. Geophys. Res. 100, 16,241-16,247.

Lean, J., Skumanich, A. and White, O. 1992. Estimating the Sun's radiative output during the Maunder Minimun. Geophys. Res. Lett. 19, 1591-1594.

Lean, J., Beer, J. and Bradley, R. 1995.Reconstruction of solar irradiance since 1600: implications for climate change. Geophys. Res. Lett. 22, 3195-3198. 
Mann, M. E., Bradley, R. S. and Hughes, M. K. 1998. Global-scale temperature patterns and climate forcing over the past six centuries. Nature 392, 779-787.

Mann, M. E., Bradley, R. S. and Hughes, M. K. 1999. Northern hemisphere temperature during the past millenium: inferences, uncertainties and limitations. Geophys. Res. Lett. 26, 759-762.

Mitchell, J. F. B. and Johns, T. C. 1997. On the modification of global warming by sulphate aerosols. J. Climate 10, 245-267.

Nakazawa, T., Machida, T., Tanaka, M., Fujii, Y., Aoki, S. and Watanabe, O. 1993. Differences of the atmospheric $\mathrm{CH}_{4}$ concentration between the Arctic and Antarctic regions in pre-agricultural era. Geophys. Res. Lett. 20, 943-946.

Ohring, G. and Hadler, S. 1978. Some experiments with a zonally-averaged climate model. J. Atmos. Sci. $\mathbf{3 5}$ 186-205.

Örn, G., Hansson, U. and Rodhe, H. 1996. Historical worldwide emissions of anthropogenic sulfur: 1860-1985. Report CM-91, ISSN 0280-445X. Department of Meteorology, Stockholm University. International Meteorological Institute in Stockholm, Sweden, $20 \mathrm{pp}$.

Parker, D. E., Folland, C. K. and Jackson, M. 1995 Marine surface temperature: observed variations and data requirements. Clim. Change 31, 559-600.

Parkinson, C. L. and Washington, 1979. A large-scale numerical model of sea ice. J. Geophys. Res. 84 311-337.

Penner, J. E., Dickinson, R. and O’Neill, C. 1992. Effects of aerosol from biomass burning on the global radiation budget. Science 256, 1432-1434.

Penner, J. E., Charlson, R. J., Hales, J. M., Laulainen, N., Leifer, R., Novakov, T., Ogren, J., Radke, L. F., Schwartz, S. E. and Travis, L. 1994. Quantifying and minimizing uncertainty of climate forcing by anthropogenic aerosols. Bull. Am. Met. Soc. 75, 375-400.

Pollack, J. B., Toon, O. B., Sagan, C., Summers, A. Baldwin, B. and Van Camp, W. 1976. Volcanic explosions and climatic change: a theoretical assesment. J. Geophys. Res. 81, 1071-1083.

Pollack, J. B., Toon, O. B. and Wiedman, D. 1981. Radiative properties of the background stratospheric aerosols and implications for perturbed conditions Geophys. Res. Lett. 8, 26-28.

Reid, G. C. 1997. Solar forcing of global climate change since the mid-17th century. Clim. Change 37, 391-405.

Robock, A. and Mao, J. 1995. The volcanic signal in surface temperature observations. J. Climate $\mathbf{8}$, 1086-1103.

Saltzman, B. 1980. Parametrization of the vertical flux of latent heat at the Earth's surface for use in statistical-dynamical climate models. Arch. Met. Geoph. Biokl. A29, 41-53.

Saltzman, B. and Ashe, S. 1976. Parametrization of the monthly mean vertical heat transfer at the Earth's surface. Tellus 28, 323-331.
Sato, M., Hansen, J. E., McCormick, M. P. and Pollack, J. B. 1993. Stratospheric aerosol optical depth, 1850-1990. J. Geophys. Res. 98, 22,987-22,994.

Schmittner, A., Appenzeller, C. and Stocker, T. 2000. Validation of parameterisations for the meridional energy and moisture transport used in simple climate model. Clim. Dyn. 16, 63-77.

Sela, J. and Wiin-Nielsen, A. 1971. Simulation of the atmospheric annual energy cycle. Mon. Wea. Rev. 99 , 460-468.

Sellers, W. D. 1973. A quasi-three-dimensional climate model. J. Appl. Meteor. 22, 1557-1574.

Sigurdsson, H. 1982. Volcanic pollution and climate: the 1783 Laki eruption. EOS Trans. Amer. Geophys. Union 63, 601-603.

Semter, A. J. 1976. A model for the thermodynamic growth of sea ice in numerical investigations of climate. J. Phys. Oceanogr. 6, 379-389.

Semter, A. J. 1986. Finite-difference formulation of a world ocean model, in Advanced physical oceanographic numerical modelling, O'Brien (Eds.). D. Reidel, Dordrecht, 187-202.

Solanki, S. K. and Fligge, M. 1998. Solar irradiance since 1874 revisited. Geophys. Res. Lett. 25, 341-344.

Stott, P. A., Tett, S. F. B, Jones, G. S., Allen, M. R., Mitchell, J. F. B. and Jenkins, G. J. 2000. External control of 20th century temperature by natural and anthropogenic forcings. Science 290, 2133-2137.

Stott, P. A., Tett, S. F. B, Jones, G. S., Allen, M. R., Ingram, W. J. and Mitchell, J. F. B. 2001. Attribution of twentieth century temperature change to natural and anthropogenic causes. Climate Dyn. 17, 1-21.

Stouffer, R. J., Manabe, S. and Vinnikov, K. Va. 1994. Model assessment of the role of natural variability in recent global warming. Nature 367, 634-636.

Taylor, K. 1976. The influence of subsurface energy storage on seasonal temperature variations. J. Appl. Meteor. 15, 1129-1138.

Tegen, I. and Fung, I. 1995. Contribution to the atmospheric mineral aerosol load from land surface modification. J. Geophys. Res. 100, 18,707-18,726.

Tett, S. F. B, Stott, P. E., Allen, M. R., Ingram, W. J. and Mitchell, J. F. B. 1999. Causes of twentieth-century temperature change near the Earth's surface. Nature 399, 569-572.

Thomson, D. J. 1982. Spectrum estimation and harmonic analysis. IEEE Proc. 70, 1055-1096.

Thomson, D. J. 1990. Quadratic-inverse spectrum estimates: applications to palaeoclimatology. Phil. Trans. Roy. Soc. A332, 539-597.

Tricot, Ch. and Berger, A. 1987. Modelling the equilibrium and transient responses of global temperature to past and future trace gas concentrations. Climate Dyn. 2, 39-61.

Twomey, S. 1974. Pollution and planetary albedo. Atmos. Environ. 8, 1251-1256.

Wright, D. G. and Stocker, T. F. 1992. Sensitivities of a zonally averaged global ocean circulation model. J. Geophys. Res. 97, 12,707-12,730.

Zhang, Q., Soon, W. H., Baliunas, S. L., Lockwood,

Tellus 54A (2002), 3 
G. W., Skiff, B. A. and Radick, R. R. 1994. A method of determining possible brightness variations of the Sun in past centuries from observations of solar-type stars. Astrophys. J. 427, L111-L114.
Zielinski, G. A. 1995. Stratospheric loading and optical depth estimates of explosive volcanism over the last 2100 years derived from the Greenland Ice Sheet Project 2 Ice core. J. Geophys. Res. 100, 20,937-20,955. 